\title{
Role of Cardiac Imaging: Echocardiography
}

\author{
Bruno Pinamonti, Elena Abate, Antonio De Luca, \\ Gherardo Finocchiaro, and Renata Korcova
}

\section{Abbreviations and Acronyms}

2D Two-dimensional

3D Three-dimensional

AC Arrhythmogenic cardiomyopathy

CFR Coronary flow reserve

CMR Cardiac magnetic resonance

CRT Cardiac resynchronization therapy

CT Computed tomography

DCM Dilated cardiomyopathy

DSE Dobutamine stress echocardiography

EDV End-diastolic volume

EF Ejection fraction

EROA Effective regurgitant orifice area

ESV End-systolic volume

FAC Fractional area change

B. Pinamonti $(\triangle) \cdot$ A. De Luca $\cdot$ R. Korcova

Cardiovascular Department, Azienda Sanitaria Universitaria Integrata, University of Trieste (ASUITS), Trieste, Italy

E. Abate

Cardiovascular Department, Azienda Sanitaria Universitaria Integrata, University of Trieste (ASUITS), Trieste, Italy

Klinik für Innere Medizin 3, Universitätsklinikum Halle (Saale), Halle (Saale), Germany e-mail: Elena.Abate@uk-halle.de

G. Finocchiaro

Cardiology Clinical and Academic Group, St George's, University of London, London, UK

e-mail: gfinocch@sgul.ac.uk 


$\begin{array}{ll}\text { GLS } & \text { Global longitudinal strain } \\ \text { ICD } & \text { Implantable cardioverter defibrillator } \\ \text { LA } & \text { Left atrial } \\ \text { LBBB } & \text { Left bundle branch block } \\ \text { LGE } & \text { Late gadolinium enhancement } \\ \text { LV } & \text { Left ventricular } \\ \text { LVRR } & \text { Left ventricular reverse remodeling } \\ \text { MR } & \text { Mitral regurgitation } \\ \text { MV } & \text { Mitral valve } \\ \text { NYHA } & \text { New York Heart Association } \\ \text { PISA } & \text { Proximal isovelocity surface area } \\ \text { PW } & \text { Pulsed wave } \\ \text { RV } & \text { Right ventricular } \\ \text { RVol } & \text { Regurgitant volume } \\ \text { SDI } & \text { Systolic dyssynchrony index } \\ \text { STE } & \text { Speckle-tracking echocardiography } \\ \text { TAPSE } & \text { Tricuspid annular peak systolic excursion } \\ \text { TDI } & \text { Tissue Doppler imaging } \\ \text { TR } & \text { Tricuspid regurgitation } \\ \text { WMSI } & \text { Wall motion score index }\end{array}$

\subsection{Echocardiographic Features of Dilated Cardiomyopathy}

Echocardiography has crucial importance in the diagnosis of dilated cardiomyopathy (DCM). Indeed, it is still considered as the main tool for both diagnosis and follow-up of patients with DCM. Main echocardiographic features of dilated cardiomyopathy (DCM) are summarized in Table 7.1 [1-3]. DCM is defined in the presence of left ventricular (LV) ejection fraction (EF) $<45 \%$ and LV end-diastolic diameter $>2.7 \mathrm{~cm} / \mathrm{m}^{2}$ or $>117 \%$ predicted value corrected for age and body surface area $[1,3,4]$.

The hallmark of the disease is a global LV dilation (Fig. 7.1). With the progression of the disease, the LV shows a change in its geometry becoming more spherical, with increased short axis/long axis ratio (sphericity index) [5] (Fig. 7.2). In a minority of cases of DCM, the LV end-diastolic diameter is still within $15 \%$ of normal values. This entity is classified as "mildly dilated cardiomyopathy" [6].

LV dilation can usually be accompanied by LV eccentric hypertrophy, with normal or only mildly increased LV wall thickness and increased LV mass (due to LV dilation). This feature is important for differential diagnosis between idiopathic DCM and other causes of dysfunction, such as end-stage hypertrophic cardiomyopathy and infiltrative or hypertensive heart disease.

Diffuse hypokinesis is typically seen in DCM, although regional wall motion abnormalities with akinesis or dyskinesis may be noticed, mostly at LV septum or apex, while better contractility is more common in the posterior and lateral walls. 
Table 7.1 Echocardiographic features of DCM

\begin{tabular}{|c|c|c|}
\hline $\begin{array}{l}\text { Echocardiographic } \\
\text { parameters }\end{array}$ & Cutoff/features & Comments \\
\hline LV dilatation & $\begin{array}{l}\mathrm{LV} \text { end-diastolic diameter } \\
>2.7 \mathrm{~cm} / \mathrm{m}^{2} \text { or }>117 \% \\
\text { predicted value corrected } \\
\text { for age and body surface } \\
\text { area } \\
\text { Increased sphericity index } \\
\text { is common }\end{array}$ & $\begin{array}{l}\text { Not necessary for diagnosis (e.g., mildly } \\
\text { dilated cardiomyopathy) }\end{array}$ \\
\hline $\begin{array}{l}\text { LV systolic } \\
\text { dysfunction }\end{array}$ & $\mathrm{EF}<45 \%$ & Impaired global contractility \\
\hline $\begin{array}{l}\text { LV wall motion } \\
\text { abnormalities }\end{array}$ & Diffuse hypokinesis & $\begin{array}{l}\text { Possible regional wall motion abnormalities } \\
\text { mostly in LV septum and apex }\end{array}$ \\
\hline LV wall thickness & $\begin{array}{l}\text { Normal or only mildly } \\
\text { increased }\end{array}$ & $\begin{array}{l}\text { Common presence of LV eccentric } \\
\text { hypertrophy }\end{array}$ \\
\hline $\begin{array}{l}\text { LV diastolic } \\
\text { dysfunction }\end{array}$ & $\begin{array}{l}\text { "Restrictive pattern" } \\
(E<150 \mathrm{~ms} \text { and } E / A \\
\text { ratio }>2) \text { is related to } \\
\text { increased LV stiffness }\end{array}$ & $\begin{array}{l}\text { Useful hallmark of advanced diastolic } \\
\text { dysfunction and elevated LV filling } \\
\text { pressure. Can vary during follow-up }\end{array}$ \\
\hline LV dyssynchrony & $\begin{array}{l}\text { Qualitative + quantitative } \\
\text { polyparametric evaluation }\end{array}$ & $\begin{array}{l}\text { Frequent if severe LV dysfunction and } \\
\text { LBBB; not a selection criteria for CRT }\end{array}$ \\
\hline $\begin{array}{l}\text { RV dilation and } \\
\text { dysfunction }\end{array}$ & $\begin{array}{l}\text { TAPSE }<14 \mathrm{~mm}, \mathrm{RV} \\
\text { FAC }<35 \%\end{array}$ & $\begin{array}{l}\text { Secondary of biventricular involvement } \\
\text { and/or pulmonary hypertension }\end{array}$ \\
\hline LA dilation & $\begin{array}{l}\text { End-systolic LA volume } \\
\text { index }>34 \mathrm{ml} / \mathrm{m}^{2}\end{array}$ & $\begin{array}{l}\text { Associated with diastolic dysfunction, MR, } \\
\text { atrial fibrillation }\end{array}$ \\
\hline Functional MR & $\begin{array}{l}\mathrm{EROA}>0.20 \mathrm{~cm}^{2} \\
\text { identifies a significant } \\
\text { functional MR }\end{array}$ & $\begin{array}{l}\text { Contributes to increase of LV filling } \\
\text { pressure and decrease of forward stroke } \\
\text { volume; increases LV adverse remodeling }\end{array}$ \\
\hline Functional TR & & $\begin{array}{l}\text { Common in presence of RV dilation and } \\
\text { dysfunction and pulmonary hypertension }\end{array}$ \\
\hline $\begin{array}{l}\text { Dobutamine or } \\
\text { exercise stress } \\
\text { echocardiographic } \\
\text { test }\end{array}$ & $\begin{array}{l}\text { Assessment of presence or } \\
\text { absence of LV inotropic } \\
\text { response; sustained } \\
\text { improvement vs. biphasic } \\
\text { response }\end{array}$ & \\
\hline
\end{tabular}

$C R T$ cardiac resynchronization therapy, $D C M$ dilated cardiomyopathy, $E F$ ejection fraction, $E R O A$ effective regurgitant orifice area, $F A C$ fractional area change, $L A$ left atrial, $L V$ left ventricular, $M R$ mitral regurgitation, $R V$ right ventricular, TAPSE tricuspid annular peak systolic excursion, $T R$ tricuspid regurgitation

The presence of a coronary artery distribution of wall motion abnormalities raises the suspicion of coronary artery disease. "Idiopathic LV aneurysms" are rarely seen in DCM and should be distinguished from cases of myocarditis, sarcoidosis, or leftdominant arrhythmogenic cardiomyopathy (AC) [7].

As in other cardiac diseases, the main parameter adopted to evaluate LV systolic dysfunction with standard echocardiography is LV EF assessed with twodimensional (2D) biplane modified Simpson's rule (Fig. 7.3), with the use of contrast agents in the case of poor baseline image quality. Moreover, $\mathrm{d} P / \mathrm{d} T$ and cardiac 


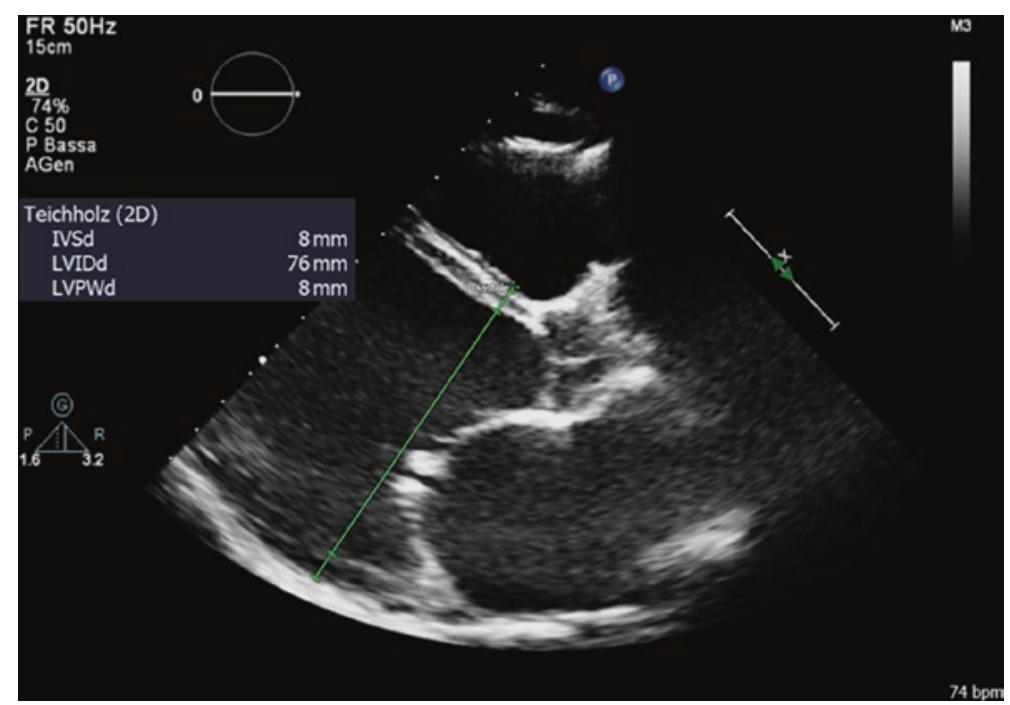

Fig. 7.1 Transthoracic echocardiography of dilated cardiomyopathy, parasternal long axis view with evidence of significant left ventricular (LV) dilatation. Of note, mitral valve annular dilatation, with leaflet tethering and reduced coaptation, is also present

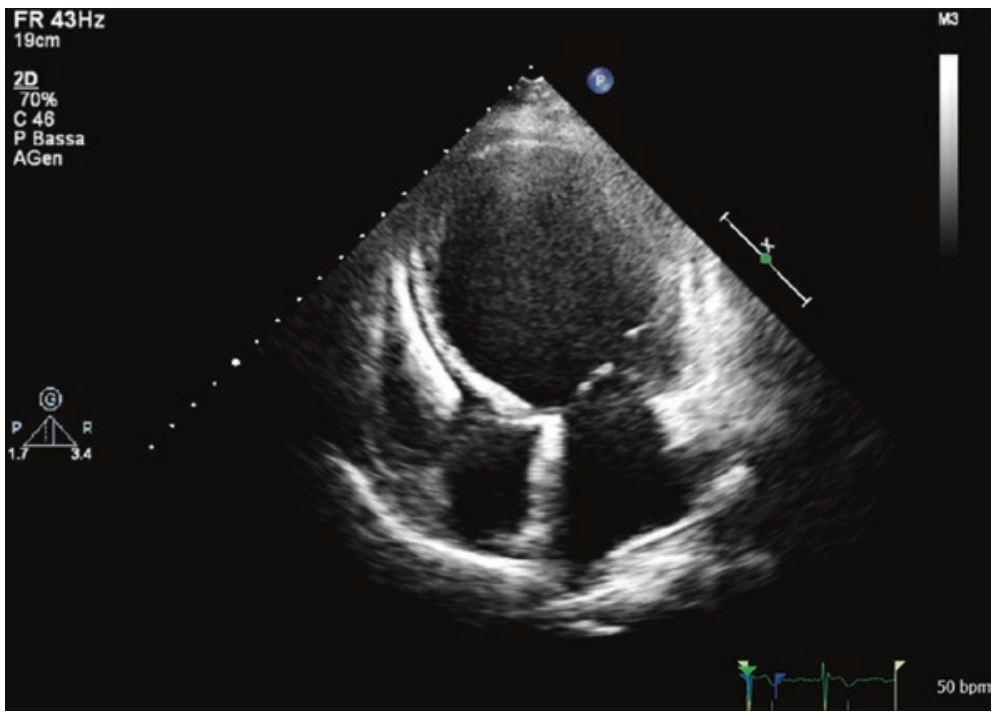

Fig. 7.2 Two-dimensional transthoracic echocardiography of dilated cardiomyopathy, apical four-chamber view. Significant left ventricular remodeling with increased sphericity and presence of implantable defibrillator lead in the right side of the heart are also seen 

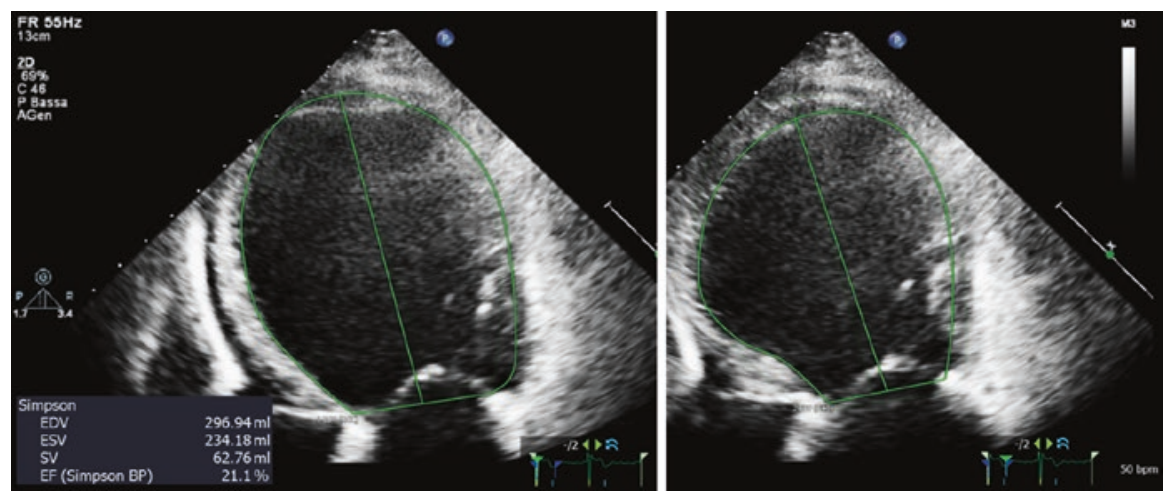

Fig. 7.3 Two-dimensional transthoracic echocardiography of dilated cardiomyopathy, apical four-chamber view. Quantification of left ventricular (LV) volumes and ejection fraction (EF) calculated using the biplane Simpson's method. Quantitative data: LV end-diastolic volume $297 \mathrm{~mL}$, LV end-systolic volume $234 \mathrm{~mL}$, LVEF $21 \%$

output are further load-dependent parameters of LV performance, frequently used in association with LV EF. Tissue Doppler imaging (TDI) mitral annulus velocity can be also reduced showing LV longitudinal dysfunction. Severe LV dilation and dysfunction can trigger development of spontaneous echocontrast and LV thrombi formation, increasing the risk of systemic thromboembolism [8].

Diastolic dysfunction is frequent in DCM, reflecting structural LV wall pathology (particularly fibrosis), and chamber remodeling. Both abnormal relaxation and increased LV stiffness are present in the disease, with resulting increased LV filling pressure. LV diastolic dysfunction can be evaluated with several echocardiographic parameters. In particular, a "restrictive LV filling pattern" (Fig. 7.4) characterized by a short deceleration time of $E(<150 \mathrm{~ms})$ and an increased $E / A$ ratio $(>2)$ at transmitral inflow pulsed Doppler tracing is related to increased LV stiffness and filling pressures and usually reflects a more advanced stage of the disease. Frequently the restrictive filling pattern is associated with severe LV dilation, systolic dysfunction, left atrial (LA) dilation, right ventricular (RV) involvement, and functional MR [9]. On another side, an increased $E / E^{\prime}$ ratio (i.e., early diastolic mitral filling $E /$ early diastolic mitral annular velocity $E^{\prime}$ at TDI) strongly correlates with diastolic dysfunction and increased LV filling pressure.

Additional indices useful to evaluate diastolic dysfunction are the response of the mitral flow pattern to Valsalva maneuver, the pattern of pulmonary venous Doppler curve, and LA dilation (Fig. 7.5). The latter is frequent in DCM and depends on multiple factors (severity and duration of the disease, LV filling pressure, presence and severity of MR, presence of atrial fibrillation). Changes in diastolic pattern can be seen during the course of the disease, i.e., worsening or improvement after optimal treatment [10].

LV mechanical dyssynchrony is another important aspect that can be evaluated with echocardiography in DCM patients with heart failure, LV systolic dysfunction, and left bundle branch block (LBBB). Echocardiography provides a multiparametric 

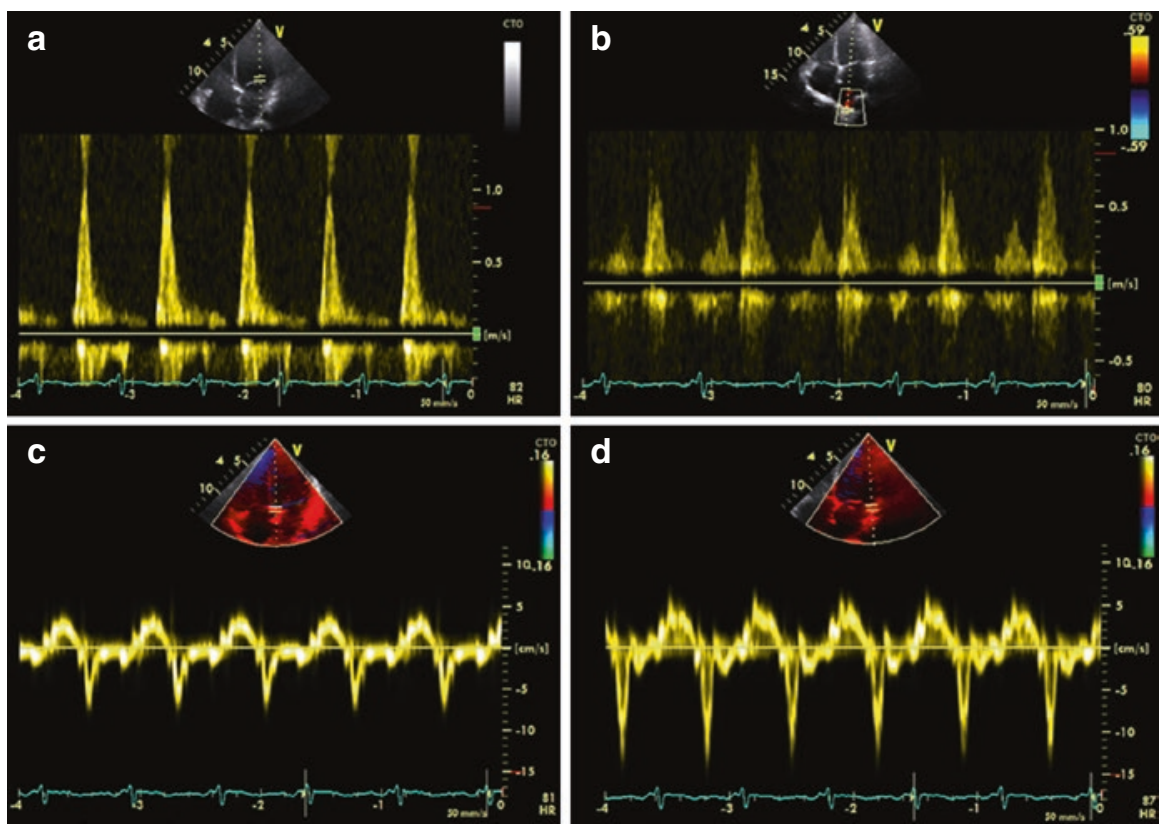

Fig. 7.4 Case of dilated cardiomyopathy with severe diastolic dysfunction. Panel (a) pulsed-wave Doppler at mitral valve inflow. Predominant $E$ wave with rapid deceleration time and increased $E / A$ ratio, consistent with restrictive filling pattern. Quantitative data: $E$ wave $1.1 \mathrm{~m} / \mathrm{s}, E$ wave deceleration time $100 \mathrm{~ms}, A$ wave $0.2 \mathrm{~m} / \mathrm{s}, E / A$ ratio 5.5. Panel (b) pulsed-wave Doppler of the pulmonary vein flow, with predominance of diastolic flow, compatible with increased LV filling pressure. Quantitative data: $S$ wave $0.4 \mathrm{~m} / \mathrm{s}, D$ wave $0.9 \mathrm{~ms}, S / D$ ratio 0.4 , systolic fraction of the pulmonary vein velocity-time integral 0.3. Panel (c) and (d) medial and lateral tissue Doppler velocities for the estimation of the left ventricular filling pressure. Quantitative data: medial $S^{\prime}$ wave $0.04 \mathrm{~m} / \mathrm{s}$, medial $E^{\prime}$ wave $0.07 \mathrm{~m} / \mathrm{s}$, medial $A^{\prime}$ wave $0.03 \mathrm{~m} / \mathrm{s}$, lateral $S^{\prime} 0.05 \mathrm{~m} / \mathrm{s}$, lateral $E^{\prime} 0.12 \mathrm{~m} / \mathrm{s}$, lateral $A^{\prime} 0.03 \mathrm{~m} / \mathrm{s}, E / E^{\prime}$ (medial) ratio 16

qualitative and quantitative approach for assessment of LV mechanical dyssynchrony [11]. The "apical rocking" motion of the LV yields a first qualitative diagnostic hint, which should be confirmed by other indices, as "septal flash," septal to posterior wall motion delay at M-mode, and TDI-derived indices (intervals from QRS to peak systolic velocities of wall motion of different LV segments, assessing the delay between opposite LV walls). Also the presence of significant interventricular dyssynchrony, demonstrated by the time delay between the LV and RV ejections at pulsed-wave (PW) Doppler, was proven to be associated with higher probability of favorable response to CRT in DCM patients [12]. However, echo-Doppler indexes of dyssynchrony are scarcely reliable $[13,14]$, and therefore, current guidelines do not recommend echocardiography as selection criteria for CRT [15].

Functional MR in DCM is secondary to several concurrent factors. LV enlargement and mitral annulus dilation cause papillary muscle displacement and systolic retraction of mitral valve (MV) leaflets toward the LV apex resulting in leaflet malcoaptation [16] (Fig. 7.6). On the other side, MR itself increases the LV and LA 

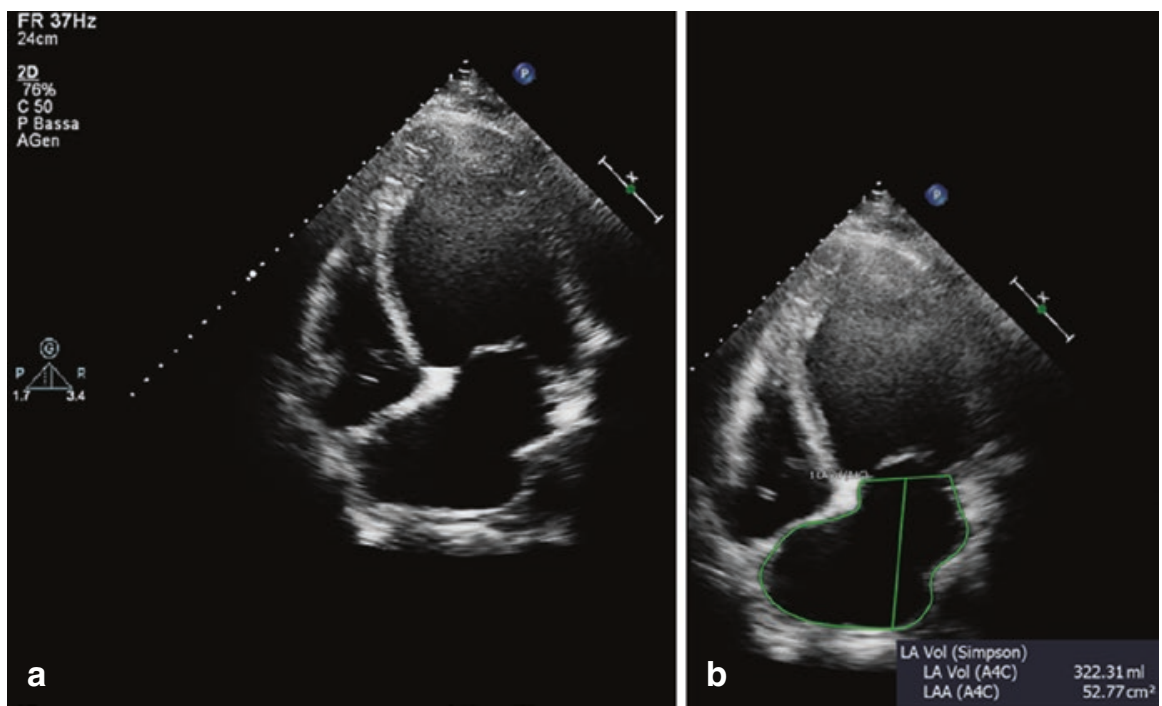

Fig. 7.5 Two-dimensional transthoracic echocardiography of an advanced case of dilated cardiomyopathy, apical four-chamber view. Panel (a) extreme remodeling of the heart chambers. Panel (b) severe left atrial enlargement

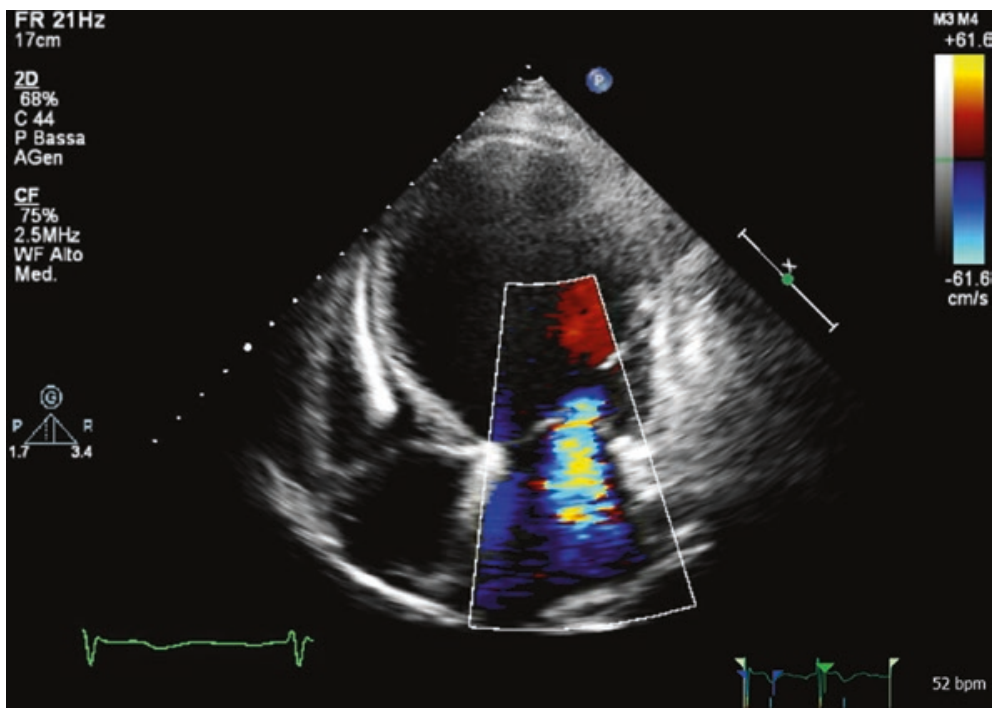

Fig. 7.6 Two-dimensional transthoracic echocardiography of dilated cardiomyopathy, apical four-chamber view, color Doppler study. Presence of significant functional mitral regurgitation due to dilatation of the mitral valve annulus and tethering of mitral valve leaflets 

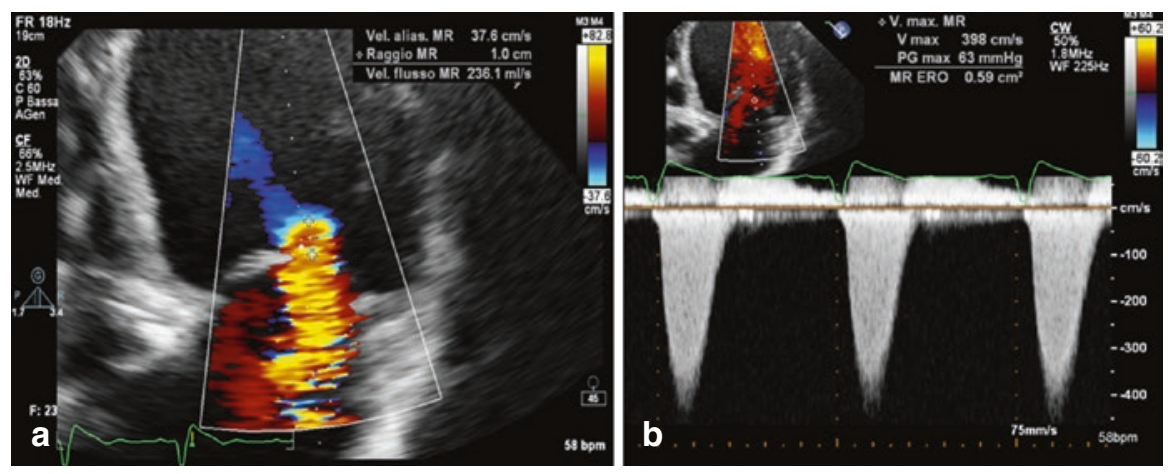

Fig.7.7 Two-dimensional transthoracic echocardiography of dilated cardiomyopathy with severe mitral regurgitation (MR). Quantification of the effective regurgitant orifice area (EROA) with the proximal isovelocity surface area (PISA) method. Panel (a) apical four-chamber view focused on mitral regurgitation jet origin for the measurement of the PISA radius. Panel (b) continuous wave Doppler of the regurgitant jet with low velocity and a triangular profile, suggestive of severe MR. Quantitative data: PISA radius $1 \mathrm{~cm}$, EROA $59 \mathrm{~mm}^{2}$

volume overload causing further LV dilation and remodeling, which consecutively escalates the degree of MR. Hemodynamically significant MR contributes to increase LA pressure and decreases LV forward stroke volume, worsening the patients' status. According to the current guidelines, a cutoff of effective regurgitant orifice area (EROA) $>0.20 \mathrm{~cm}^{2}$ identifies a significant functional MR [17] (Fig. 7.7).

Echocardiography is pivotal to assess MV morphology, quantify mitral annulus dilation, and rule out the presence of structural leaflet disease. Furthermore, it is important to evaluate MR severity with a multiparametric approach [17]. To increase sensitivity and specificity in detecting the severity of MR, transesophageal echocardiography provides the best accuracy. Indeed, transesophageal echocardiograms are capable of providing a more accurate estimation of morphological (MV annulus dilation, quantification of systolic leaflet retraction, coaptation depth, and tenting area) and functional (EROA calculated with proximal isovelocity surface area [PISA], regurgitant volume [RVol]) parameters.

RV dilation and systolic dysfunction are frequent in DCM and can represent biventricular involvement of the disease (30\% of DCM cases) and/or are secondary to RV pressure overload due to left-side disease [18, 19]. RV dysfunction correlates with worse functional status and more advanced heart failure [20]. The presence of RV dilation is usually assessed with $2 \mathrm{D}$ echocardiography from standard echo views (Fig. 7.8). RV systolic function is estimated with various parameters, as fractional area change (FAC), tricuspid annular peak systolic excursion (TAPSE), TDI, systolic tricuspid annular velocity, and RV myocardial performance index [21] (Fig. 7.9).

In the presence of RV dilation and dysfunction, functional tricuspid regurgitation (TR) and pulmonary hypertension are quite common in DCM. Pulmonary hypertension is more frequently associated with the severity of functional MR and LV 

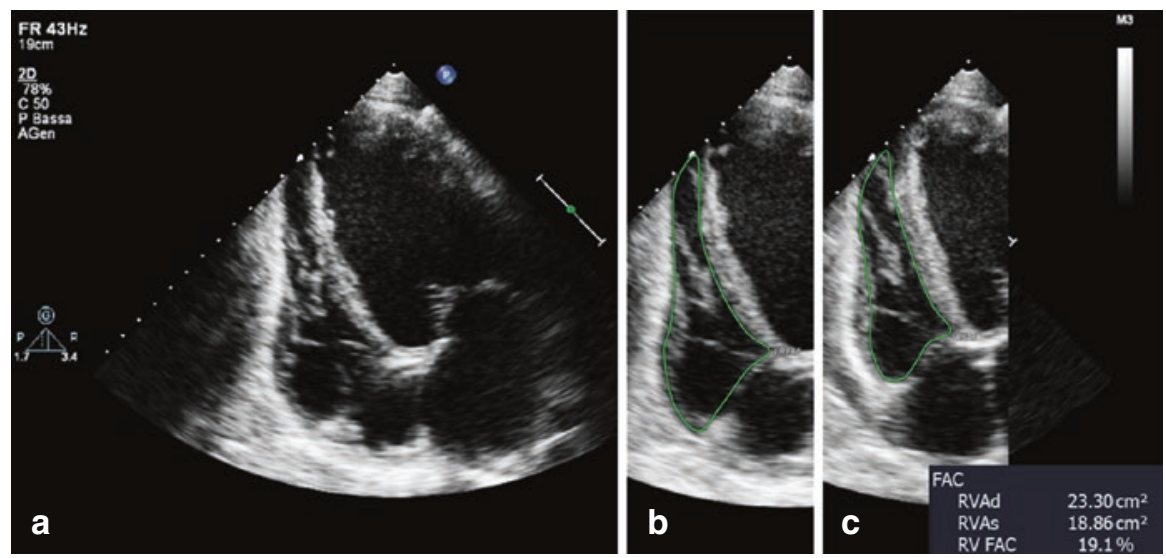

Fig. 7.8 Two-dimensional transthoracic echocardiography of dilated cardiomyopathy, apical four-chamber view focused on the right ventricle (Panel a) for RV systolic function evaluation with fractional area change (FAC) method. Panel (b) RV end-diastolic area contour. Panel (c) endsystolic area contour. Quantitative data: RV end-diastolic area $23.3 \mathrm{~cm}^{2}$, RV end-systolic area $18.86 \mathrm{~cm}^{2}$, RV FAC $19.1 \%$, consistent with severe RV systolic dysfunction
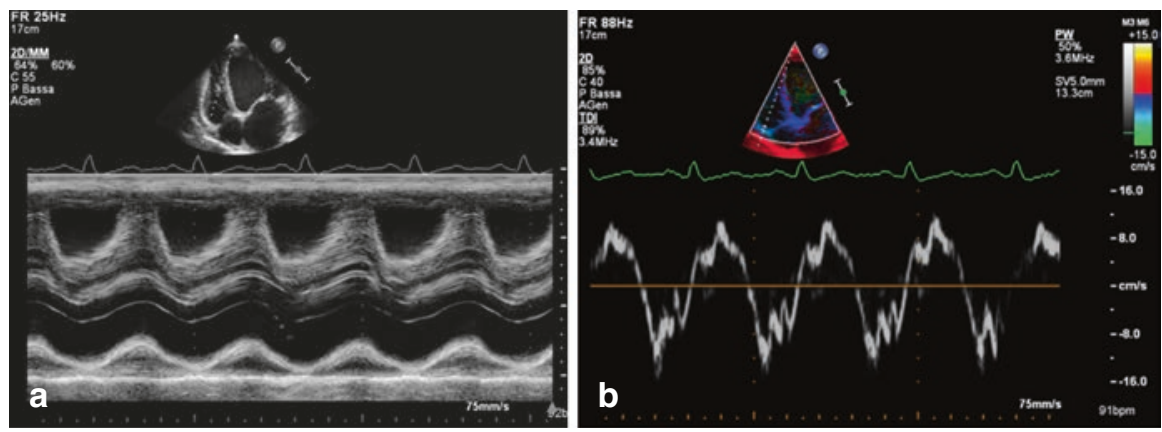

Fig. 7.9 Transthoracic echocardiography of dilated cardiomyopathy with associated right ventricular (RV) dysfunction. Assessment of right ventricular longitudinal function with M-mode tricuspid annular peak systolic excursion - TAPSE - (Panel a) and tissue Doppler $S^{\prime}$ wave velocity (Panel b). Quantitative data: TAPSE $17 \mathrm{~mm}, S^{\prime} 10 \mathrm{~cm} / \mathrm{s}$, consistent with mild RV systolic dysfunction

diastolic dysfunction than with the degree of LV systolic dysfunction [19]. In particular, patients with "restrictive" or pseudonormal mitral inflow patterns have a higher pulmonary artery systolic pressure, and the improvement to an impaired relaxation pattern appears to be followed by a significant reduction of pulmonary artery pressure [22].

Stress echocardiography can be useful in DCM to assess the myocardial contractile reserve and the presence of inducible ischemia and to evaluate the coronary flow reserve (CFR) [23]. However, to date there is no standardized protocol for stress echocardiography in patients with LV dysfunction, and the preferred 
stress technique (dobutamine, dipyridamole, or exercise) is chosen depending on the indication of the test, the exercise ability of each patient, image quality, and expertise of the center.

Exercise is the most physiological stress test, which should be used if the patient is able to exercise. However, the most used test in DCM patients is dobutamine stress echocardiography (DSE) [24]. Low-dose dobutamine is the method of choice for assessment of myocardial contractile reserve. Also dipyridamole is a feasible test that can be used to assess the contractile response; it is less arrhythmogenic and better tolerated [23]. A LV EF increase $>20 \%$ or a wall motion score index (WMSI) $>0.44$ from baseline recognizes patients with preserved contractile reserve. A biphasic response in at least two segments and/or extensive ischemic response during highdose dobutamine or exercise stress can help to identify ischemic cardiomyopathy, whereas idiopathic DCM is characterized by sustained improvement of LV function. Absence of inotropic response identifies patients with severe cardiomyopathy [23].

Dipyridamole stress test allows a combined assessment of contractile reserve and CFR on left anterior descending artery (defined by the ratio of hyperemic to rest peak diastolic flow velocity, normal value $>2.5$ ). CFR is often reduced in DCM, and it is associated with the functional class and the oxygen consumption.

DSE can also be useful to unmask a significant LV intraventricular dyssynchrony [25] and helps to identify potential responders to CRT (together with the presence of contractile reserve). Furthermore, it can be used to discriminate between true aortic valve stenosis and pseudo-stenosis combined with DCM [23]. However, to date, indications for stress echocardiography in the setting of functional MR in idiopathic DCM are controversial [26].

Importantly, many of the aforementioned echocardiographic parameters, evaluated at baseline and at follow-up, are crucial for the prognostic stratification of DCM patients (see paragraph on prognostic role of echocardiography in DCM) and are useful to evaluate the progression of the disease and the response to therapy.

\subsection{Role of New Echocardiographic Techniques}

Technological advances in the field of cardiac ultrasound have led to new noninvasive techniques, such as 3D echocardiography, TDI, and speckle-tracking echocardiography (STE). These techniques have demonstrated a significant incremental value over basic echocardiography [2, 27-29].

Accurate LV volume and EF quantification is crucial in the echocardiographic evaluation of patients with DCM. However, it is well known that M-mode and 2D evaluation of LV volumes and EF have limitations [30]. LV volume measurement by 2D echocardiography is highly dependent on user's experience (in manually tracing of endocardium and in visualization of perpendicular imaging planes), and this approach relies on geometrical assumption about the shape of the LV. The greatest advantage of 3D echocardiography in the evaluation of the LV includes independence from geometric assumption, semiautomatic delineation of the endocardium border, and the absence of errors deriving from "foreshortening" of the LV apex [31,32]. 
Fig. 7.10 Three-

dimensional reconstruction of left ventricular (LV) volumes. Severe LV dilatation and remodeling. Quantitative data: LV end-diastolic volume $307 \mathrm{~mL}, \mathrm{LV}$ end-systolic volume $234 \mathrm{~mL}, \mathrm{LV}$ ejection fraction $24 \%$, 3D global longitudinal strain (GLS) $-8.4 \%$

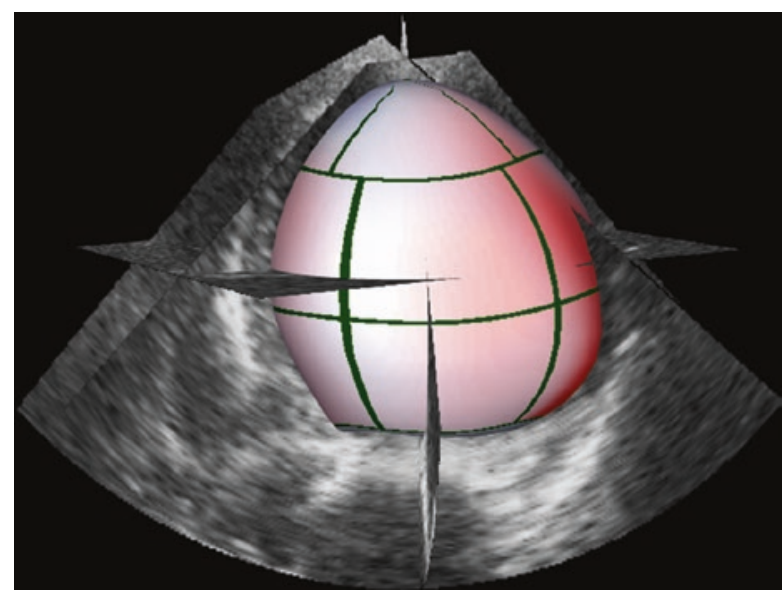

With 3D echocardiography, only one acquisition is needed to obtain volumes and $\mathrm{EF}$ and provides the possibility for quantitative assessment of LV regional wall motion by measuring the volume change of each segment in the cardiac cycle (Fig. 7.10). Three-dimensional measurements and reporting of LV volumes are recommended when feasible, depending on image quality and center expertise. Threedimensional echocardiography demonstrated high feasibility in DCM patients [33] and has been extensively validated against cardiac magnetic resonance (CMR). It has been demonstrated to be more time-saving, reproducible, and accurate than conventional 2D echocardiography for LV volumes, mass, and EF measurements, with lower inter- and intra-observer variability [34-37]. Three-dimensional echocardiography slightly underestimates both LV EDV and ESV in comparison with those measured with CMR. A recent meta-analysis of 23 studies comparing 3D echocardiography with CMR volumes and EF demonstrated biases of $-19 \pm 34 \mathrm{~mL}$, $-10 \pm 30 \mathrm{~mL}$, and $-1 \pm 12 \%$ for LV EDV and ESV and EF, respectively [38]. The lower spatial resolution of 3D echocardiography compared to CMR is responsible for this underestimation. With 3D echocardiography, it is often difficult to identify the endocardial-trabecular border and the blood-trabecular interface. In a review of sources of error, it was shown that the agreement between 3D echocardiography and CMR improved when the trabeculae were excluded from the LV cavity [39].

Technological advances in the field of cardiac ultrasound have led to further new noninvasive techniques, such as TDI and STE, for assessing cardiac mechanics and segmental and global LV function. The peak systolic myocardial velocity $S^{\prime}$, a simple TDI index of systolic longitudinal function, is a marker of impaired subendocardial fiber contraction and correlates with myocardial fibrosis [40]. STE has emerged as a novel technology to detect myocardial abnormalities. Strain analysis allows discrimination between active and passive movement of myocardial segments and permits separate assessment of distinct components of myocardial deformation (longitudinal and circumferential shortening, radial thickening, rotation, and twisting). Patients with DCM have an increased LV mass and volume and typically 
decreased contractility of the LV walls [41]. These changes lead to impaired strain in all direction (longitudinal, radial, and circumferential) [42-45].

Strain echocardiography is important for the arrhythmic risk stratification of patients with DCM since global longitudinal strain (GLS) is a promising marker of arrhythmias. Mechanical dispersion predicted arrhythmic events in patients with DCM independently of LV EF [46]. Speckle-tracking longitudinal deformation has also a potential role in assessing fibrosis as detected by contrast CMR late gadolinium enhancement (LGE), but the relationship between myocardial fibrosis and segmental strain is still not well established, especially in setting of DCM. In a small prospective study, abnormal 3D speckle-tracking GLS could detect LGEdeterminant myocardial fibrosis with a sensitivity of $85 \%$, a specificity of $85 \%$, a positive predictive value of $69 \%$, and a negative predictive value of $93 \%$, considering an optimal GLS cutoff value of $-15.25 \%$ [47].

LV twist and torsion have been investigated with different measurement methods during the past two decades, using tagged CMR as the gold standard [48]. Many studies using different echocardiographic techniques, like TDI, STE, velocity vector imaging, and 3D STE, showed that LV torsion (twisting and untwisting) represents an important mechanism for both ejection and filling. LV twist/torsion indexes are significantly impaired in patients with DCM correlating with worse functional capacity and LV function $[42,49,50]$. Reduced LV torsion in patients with DCM was found to be a predictor of response to CRT and increased after 8 months of therapy [51].

The accuracy of LV mass determined by 3D echocardiography is similar to that of CMR in most patients, showing only a slight overestimation [37, 52, 53].

Advanced indices of LV intraventricular mechanical dyssynchrony are based on TDI, speckle-tracking imaging, and 3D echocardiography [11]. As stated in the previous paragraph, the role of echocardiography in assessing LV mechanic dyssynchrony in DCM patients remains controversial to date. The Predictors of Response to Cardiac Resynchronization Therapy (PROSPECT) trial examined the predictive value of 12 echocardiographic parameters of dyssynchrony, including both conventional- and TDI-based methods, showing only a modest sensitivity and specificity of these markers [54]. Three-dimensional echocardiography has been used as a technique for dyssynchrony quantification. The systolic dyssynchrony index (SDI) is calculated as the standard deviation of regional ejection time (time to reach minimal volume). Three-dimensional echocardiography allows evaluating all LV segments simultaneously, displaying a "bull's eye" map, which demonstrates the time required to each segment to reach minimal volume. Three-dimensional echocardiographyderived LV SDI was described as highly predictive of response to CRT at $48 \mathrm{~h}$ [55], 6 months [56, 57], and 1 year of follow-up [58]. Benefits from CRT have been defined as a $\geq 15 \%$ reduction in LV ESV at follow-up [56-58], which can also readily be measured by $3 \mathrm{D}$ echocardiography.

Several groups have addressed analysis of LV strain of opposite walls by STE as the ideal technique for the assessment of LV intraventricular dyssynchrony [14, 59, 60]. Radial strain values were demonstrated to be reliable indexes of LV mechanical 
dyssynchrony useful to identify potential responders to CRT [59]. The Speckle Tracking and Resynchronization (STAR) study demonstrated that radial and transverse LV strain values were significantly related to LV EF response and long-term outcome after CRT [60]. On the other hand, absence of radial or transverse dyssynchrony ( $\geq 130 \mathrm{~ms}$ time difference in peak strain values between opposing segments) at baseline was an adverse prognostic factor after CRT [60]. In one study pacing at the site of the latest mechanical activation, as determined by speckle-tracking radial strain analysis, resulted in superior echocardiographic response after 6 months of CRT and better prognosis during long-term follow-up. Moreover, the demonstration of scar tissue by speckle-tracking GLS was found to be an independent predictor of lack of response to CRT and was related to the total scar burden assessed with CMR [61]. Furthermore, 3D speckle-tracking strain indices have been studied to quantify dyssynchrony before and after CRT [62].

For the echocardiographic assessment of LV diastolic dysfunction in patients with DCM, the ratio of early diastolic transmitral flow velocity to early diastolic annular velocity $\left(E / E^{\prime}\right)$ is frequently used to predict an increase in LV filling pressure. This approach, however, has several limitations, and its accuracy is questionable, particularly in patients with advanced DCM and severe heart failure. A study with invasive hemodynamic assessment as gold standard showed that $E / E^{\prime}$ ratio had a weak correlation with LV filling pressure in DCM, particularly those with severe LV dilatation and after CRT [63]. Other new indices for LV diastolic dysfunction evaluation obtained by speckle-tracking techniques analysis are promising. Circumferential strain and strain rate during late diastolic LV filling, E/circumferential strain rate at early diastolic LV filling, and E/circumferential strain at the time of peak $E$ wave had greater area under the curve than the $E / E^{\prime}$ ratio for the prediction of pulmonary capillary wedge pressure $>12 \mathrm{mmHg}$ [64].

Importantly, 2D LA strain assessment with speckle-tracking technique demonstrated a better correlation than other Doppler indices, such as $E / E^{\prime}$ ratio, with LV filling pressure as measured by right catheterization, in patients with advanced systolic heart failure [65]. In particular, the peak atrial longitudinal strain that corresponds to LA expansion during the reservoir phase is reduced in the presence of an increased LA pressure, and this parameter could be useful in the multiparametric assessment of LV filling pressure. In addition, LA strain represents a promising noninvasive technique to assess left atrial pump function in patients with DCM. Twodimensional STE-based LA function is impaired in patients with nonischemic DCM [66]. In a study with 134 patients with either idiopathic or ischemic DCM, LA systolic deformation was more depressed in idiopathic compared with ischemic DCM and was closely associated with functional capacity during effort. LA lateral wall systolic strain and LA volume were powerful independent predictors of peak oxygen consumption during cardiopulmonary exercise testing [67].

Quantification of MR is challenging and should be performed by using 2D or 3D vena contracta and PISA method $[17,68]$. It is well known that the $2 \mathrm{D}$ vena contracta and PISA method have several limitations. These methods assume the EROA is nearly circular, and the exact shape and size might not be accurately assessed due 
to the limited scan plane orientation of 2D echocardiography. Real-time 3D echocardiography is now available to overcome this limitation, which is particularly relevant in patients with functional MR, in whom EROA geometry is usually complex and asymmetric [69-71]. The direct measurement of the regurgitation orifice area with 3D echocardiography avoids the underestimation of its size, independently from the eccentricity of the MR jet or from cardiac rhythm [72, 73]. Quantification of RVol of functional MR with 3D echocardiography showed excellent correlation with RVol measured by CMR $(r=0.94)$, without a significant difference between these techniques (mean difference $=-0.08 \mathrm{~mL} / \mathrm{beat}$ ). Conversely, 2D echocardiography approach from the four-chamber view significantly underestimated $\mathrm{RVol}(r=0.006)$ as compared with CMR (mean difference $=2.9 \mathrm{~mL} / \mathrm{beat}$ ) [73]. Currently, dedicated MV analysis softwares allow a fast, complete, and reproducible evaluation of MV anatomy and function (MV annulus dimensions, MV annulus displacement, MV leaflet surface, tenting volume, aortomitral angle, and papillary muscle geometry) [74-76]. Furthermore, 3D transesophageal echocardiography plays an important role in the selection of patients for MitraClip, in the echocardiographic guidance of the procedure and in the pre- and post-procedural MR quantification [77].

Multiparametric advanced echocardiographic assessment of RV includes the measurement of volumes and EF by 3D technology and semiautomatic software quantification and analysis of RV longitudinal strain by 2D and 3D speckle-tracking technology (Fig. 7.11). Reduced RV strain and 3D RV EF are associated with decreased exercise capacity in DCM $[78,79]$.

Fig. 7.11 Three-

dimensional reconstruction of right ventricular $(\mathrm{RV})$ volumes. Severe RV dysfunction. Quantitative data: RV end-diastolic volume $109 \mathrm{~mL}, \mathrm{RV}$ end-systolic volume $92 \mathrm{~mL}, \mathrm{RV}$ ejection fraction $15 \%, 3 \mathrm{D}$ longitudinal strain of the free-wall $-11.5 \%$

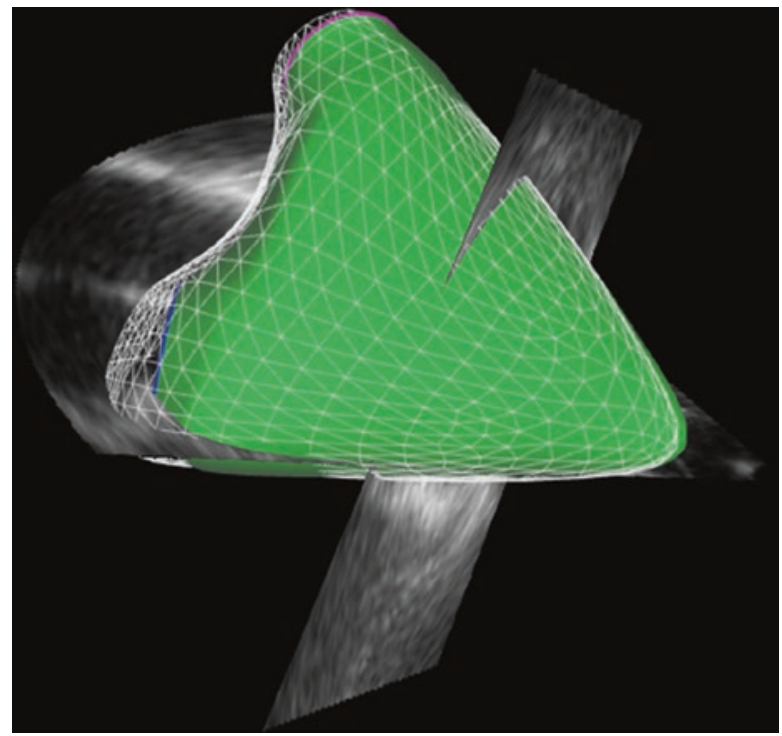




\subsection{Clinical Echocardiography in DCM: Advantages and Limitations in Clinical Practice}

Echocardiography is the first-level imaging tool, which plays a valuable role in many steps of the clinical management of patients with DCM. These include primarily the diagnosis of DCM and its differentiation from other diseases causing LV dysfunction in heart failure patients (Table 7.2) $[1,2,27,28]$. The echocardiographic demonstration of LV dilation and systolic dysfunction is diagnostic for DCM but only after exclusion of other specific causes of heart disease. The differential

Table 7.2 Echocardiographic clues in differential diagnosis of DCM

\begin{tabular}{|c|c|}
\hline Echocardiographic features & Possible differential diagnosis vs. DCM \\
\hline Associated significant LV hypertrophy & $\begin{array}{l}\text { 1. Advanced hypertrophic cardiomyopathy } \\
\text { 2. Advanced infiltrative/storage cardiomyopathy } \\
\text { 3. Advanced hypertensive heart disease }\end{array}$ \\
\hline $\begin{array}{l}\text { Segmental wall motion abnormalities } \\
\text { with coronary artery distribution }\end{array}$ & Ischemic cardiomyopathy \\
\hline $\begin{array}{l}\text { Biphasic response in at least two LV } \\
\text { segments and/or extensive ischemic } \\
\text { response during high-dose dobutamine } \\
\text { or exercise stress }\end{array}$ & Ischemic cardiomyopathy \\
\hline $\begin{array}{l}\text { Wall motion abnormalities with } \\
\text { non-coronary distribution/idiopathic } \\
\text { LV aneurysms }\end{array}$ & $\begin{array}{l}\text { 1. Left-dominant or biventricular AC } \\
\text { 2. Myocarditis } \\
\text { 3. Cardiac sarcoidosis }\end{array}$ \\
\hline Prevalent RV dilation and dysfunction & $\begin{array}{l}\text { 1. Arrhythmogenic RV cardiomyopathy with } \\
\text { biventricular involvement } \\
\text { 2. Congenital heart disease } \\
\text { 3. Pulmonary hypertension }\end{array}$ \\
\hline Presence of RV/LV aneurysms & $\mathrm{AC}$ \\
\hline $\begin{array}{l}\text { Low-gradient aortic valve } \\
\text { stenosis + LV dysfunction }\end{array}$ & $\begin{array}{l}\text { True severe aortic valve stenosis vs. pseudo-severe } \\
\text { aortic stenosis + DCM > differentiation by response } \\
\text { to DSE }\end{array}$ \\
\hline Significant MR + LV dysfunction & $\begin{array}{l}\text { Functional MR+DCM vs. organic MR + secondary } \\
\mathrm{LV} \text { dysfunction }>\text { through } \\
\text { transthoracic }+ \text { transesophageal echocardiography } \\
\text { assessment of MV }\end{array}$ \\
\hline $\begin{array}{l}\text { LV dysfunction without severe } \\
\text { dilation, LV hypertrophy, non- } \\
\text { coronary wall motion abnormalities, } \\
\text { LV thrombi }\end{array}$ & Myocarditis \\
\hline $\begin{array}{l}\text { Reversibility of pathological } \\
\text { echocardiographic parameters once } \\
\text { the causal factors are removed }\end{array}$ & $\begin{array}{l}\text { Other cardiomyopathies: inflammatory, alcoholic, } \\
\text { tachycardia-induced, stress-induced, chemotherapy- } \\
\text { induced, peripartum }\end{array}$ \\
\hline $\begin{array}{l}\text { Mild/moderate LV systolic } \\
\text { dysfunction without significant } \\
\text { dilation + severe diastolic dysfunction }\end{array}$ & $\begin{array}{l}\text { Mildly dilated cardiomyopathy vs. restrictive } \\
\text { cardiomyopathy }\end{array}$ \\
\hline
\end{tabular}

$A C$ arrhythmogenic cardiomyopathy, DCM dilated cardiomyopathy, DSE dobutamine stress echocardiography, $L V$ left ventricular, $M V$ mitral valve, $M R$ mitral regurgitation, $R V$ right ventricular 
diagnosis of various possible causes of heart failure is particularly challenging for the clinician. Therefore echocardiography provides relevant help recognizing "red flags" and directing further second-level imaging techniques, in order to obtain the final diagnosis [80, 81].

"Red flags" echocardiographic clues can raise the suspicion of a diagnosis but are however not totally specific for a definitive etiology. For example, documentation of LV dysfunction, not necessarily associated with LV hypertrophy, in patients with history of systemic hypertension may clarify the cause of LV dysfunction as endstage dilated and hypokinetic phase of hypertensive heart disease that may mimic a DCM [82]. Also multivessel coronary heart disease can be indistinguishable by echocardiography from DCM, and sometimes only coronary angiography clarifies the diagnosis. In some cases, a diagnostic hint originates from the evidence of segmental wall motion abnormalities with coronary distribution, as well as the proof of an ischemic "biphasic" response at DSE. Other noninvasive imaging techniques, as CMR which evaluates the LGE pattern, single-photon emission computed tomography (CT) which assesses perfusion abnormalities, and CT which depicts the coronary anatomy, are useful to differentiate ischemic from nonischemic DCM.

Regarding the differential diagnosis in the case of DCM associated with valve disease, low-dose dobutamine stress test is particularly valuable in the differentiation between a true severe aortic valve stenosis with consequent LV dysfunction and a pseudo-aortic valve stenosis in the presence of DCM. Also a severe MR can lead to advanced LV dysfunction: in this case transthoracic and transesophageal echocardiographic assessment of MV apparatus is valuable in excluding organic MV disease.

Several other cardiomyopathies can mimic the morphological features of DCM. Echocardiography can give diagnostic hints but remains often limited in defining DCM etiology, thus suggesting the use of second-level imaging investigations, primarily CMR which can recognize distinct LGE distribution in different cardiomyopathies. Myocarditis is echocardiographically characterized by LV dysfunction frequently without severe dilation, sometimes LV hypertrophy due to interstitial edema, wall motion abnormalities with non-coronary distribution, and possible presence of LV thrombi [83]. CMR in these cases facilitates the diagnosis detecting myocardial edema, but the diagnostic gold standard remains endomyocardial biopsy. AC with biventricular or "left-dominant" involvement can be suspected by echocardiography in presence of biventricular dysfunction and in presence of RV/LV aneurysms [84]. Again, the diagnostic imaging tool of choice in suspected $\mathrm{AC}$ is CMR [85]. Also advanced hypertrophic cardiomyopathy in hypokineticdilated end-stage has echocardiographic features similar to DCM with LV spherical remodeling and apparent regression of LV hypertrophy [86]. The presence of previous echocardiographic exams with documentation of severe LV hypertrophy typical of hypertrophic cardiomyopathy may help the diagnosis in these extreme cases. Of note, evidence of significant LV hypertrophy may also suggest advanced stages of infiltrative/storage cardiomyopathy [87]. Hemochromatosis causes a restrictive cardiomyopathy which progresses to an end-stage DCM with echocardiographic features undistinguishable from idiopathic DCM. Therefore, CMR is the imaging 
modality of choice to detect the iron overload in the myocardium. Also the differential diagnosis between LV non-compaction and DCM with conspicuous trabeculations secondary to LV remodeling is often possible only with CMR. Finally, other cardiomyopathies (inflammatory, alcoholic, tachycardia-induced [88], stressinduced, chemotherapy-induced, peripartum) usually show a reversibility of pathological echocardiographic parameters once the causal factors have resolved; therefore echocardiography is extremely valuable in follow-up of these patients.

Echocardiography is also important in the early diagnosis of DCM in patients with positive familiar history and/or in presence of a positive genetic mutation $[4,89$, 90]. The diagnosis of DCM is obtained in presence of two or more affected family members or in presence of a first-degree relative of a DCM patient with unexplained sudden death at $<35$ years [1]. Familiar screening including history, physical examination, ECG, and echocardiography is indicated in probands and first-degree relatives. LV dilation and reduced fractional shortening are common in asymptomatic relatives of patients with DCM and are associated with a significant risk for disease progression [90]. Advanced echocardiographic techniques as myocardial deformation imaging might permit the detection of latent DCM (with reduced strain) earlier than LV enlargement and depression of EF [91]. In controversial cases other imaging techniques as CMR, as well as follow-up reassessment, are indicated.

In addition, several echocardiographic parameters, assessed at baseline and at follow-up, are relevant for prognostic stratification of DCM patients (see paragraph about prognostic role of echocardiography in DCM) and help the clinician in assessing the progression of the disease and the response to treatment. They also guide in taking decisions not only about pharmacological therapy but also indication for invasive treatments as implantable device therapy (implantable cardioverter defibrillators (ICD), CRT, and correction of valvulopathy [92-95]). Documentation of LV $\mathrm{EF}<30 \%$, severe LV dilatation, and LV thrombosis suggests the indication for anticoagulation therapy in order to lower the risk of thromboembolism. Echocardiographic LV EF measurement is an important parameter for determining the appropriateness of ICD and CRT implantation. LV EF $\leq 35 \%$ in association with advanced New York Heart Association (NYHA) class despite optimal medical therapy for at least 3 months is considered in the indication for ICD and, if prolonged QRS is present, is an echo criterion for the selection of patients for CRT. Accurate MV echocardiographic evaluation is becoming increasingly more relevant due to the emerging role of percutaneous procedures to treat functional MR. In particular, the percutaneous mitral valve edge-to-edge repair with MitraClip implantation in heart failure patients with severe functional MR and high risk for surgery is a new therapeutic possibility. Echocardiography is fundamental not only in the selection of patients [96] but also in guiding the procedure and in the follow-up. Echocardiography can also provide assistance in the implantation of ventricular assist devices and the evaluation for heart transplantation in end-stage heart failure patients.

In conclusion, echocardiography is the first-line imaging exam in patients with DCM, and it has a pivotal role in assessing its morphological and functional features and in piloting treatment options. However, sometimes echocardiographic data are not sufficient, and they should guide further and more specific cardiac diagnostic 
investigations. General advantages of echocardiography over other imaging techniques in clinical everyday practice are its extensive availability, accessibility, and low cost. Furthermore, it is noninvasive, safe, and free from radiations and can be performed in patients with heart devices who cannot undergo magnetic fields. Limitations of echocardiography include inadequate image quality and unfeasibility for tissue characterization. Moreover, as other imaging techniques, the operators require a learning curve and adequate expertise and familiarity with the disease.

\subsection{Prognostic Role of Echocardiographic Data in DCM}

The natural history of DCM has dramatically improved in the last 20 years as a result of the introduction in clinical practice of beta-blockers, ACE inhibitors, and mineralocorticoid receptor antagonists which showed not only a reduction in mortality and morbidity but also significant improvements in terms of LV reverse remodeling (LVRR) [27, 28, 97, 98]. Therefore, studies on the prognostic role of echocardiography should be contextualized in their historical phase of conception, keeping in mind that during the last three decades, the gradual optimization of medical therapy has paralleled a significant improvement in survival [99].

The main echocardiographic parameters useful to assess the prognosis in patients with DCM are summarized in Table 7.3.

LV dilatation and systolic dysfunction are the hallmarks of the disease and markers of adverse outcome [2, 18, 27, 28, 100]. Remodeling in DCM includes other features as dyssynchronous ventricular contraction, functional MR, dilatation of other chambers, and myocardial fibrosis. Conversely, LVRR, characterized by a decrease in LV dimensions and the normalization of shape associated with a significant improvement of systolic function, is a therapeutic goal (nowadays achieved in almost $40 \%$ of patients in optimal medical and device treatment) and adds prognostic value for the stratification of long-term risk [92]. Therefore, although baseline LV EF is an independent predictor or outcome both in adults and children with idiopathic DCM [101], a serial thorough assessment of LV size and systolic function, especially after medical treatment optimization, is pivotal in the management of these patients. At approximately 24 months after diagnosis and establishment of optimal medical therapy, LVRR is considered completed; nonetheless, possible disease progression indicates the need for continuous follow-up, lifelong therapy, and evaluation of potential negative prognostic factors (including atrial fibrillation, LV restrictive filling, RV dysfunction, LBBB, functional MR) [27].

Severe LV diastolic dysfunction, characterized by restrictive filling pattern, has been demonstrated a powerful adverse prognostic sign specifically in patients with DCM, as in other patients with heart failure [9]. Furthermore, persistence of LV restrictive filling pattern is associated with high mortality and transplantation rate, while patients with reversible restrictive filling have a high probability of improvement and excellent survival [10]. Early diastolic mitral filling E/early diastolic mitral 
Table 7.3 Main echocardiographic parameters clinically useful to assess prognosis in patients with DCM

\begin{tabular}{|c|c|c|c|}
\hline & Echo parameters & Comments & References \\
\hline \multirow[t]{9}{*}{$\begin{array}{l}\text { At first } \\
\text { assessment }\end{array}$} & LV dilatation & $\begin{array}{l}\text { Larger indexed LV ESV is predictor of } \\
\text { early arrhythmic events }\end{array}$ & {$[27,120]$} \\
\hline & LV EF & Independent predictor of outcome & [101] \\
\hline & $\begin{array}{l}\text { LV diastolic } \\
\text { dysfunction }\end{array}$ & $\begin{array}{l}\text { Independent prognostic indicator of poor } \\
\text { outcome or heart transplantation }\end{array}$ & [9] \\
\hline & Functional MR & $\begin{array}{l}\text { Independently associated with a poor } \\
\text { prognosis }\end{array}$ & {$[92,106]$} \\
\hline & RV dysfunction & $\begin{array}{l}\text { Correlates with worse functional status, } \\
\text { more advanced LV failure, and has } \\
\text { prognostic importance. Biventricular } \\
\text { dilation is associated with a worse } \\
\text { prognosis as compared to isolated LV } \\
\text { dilation }\end{array}$ & {$[20]$} \\
\hline & LA enlargement & $\begin{array}{l}\text { Correlates with } \downarrow \text { exercise tolerance and } \\
\uparrow \text { pro-BNP }\end{array}$ & [105] \\
\hline & $\begin{array}{l}\text { Pulmonary artery } \\
\text { pressure }\end{array}$ & $\begin{array}{l}\text { Peak TR velocity }>2.5 \mathrm{~m} / \mathrm{s} \text { is associated } \\
\text { with increased mortality, increased } \\
\text { hospitalization, and higher incidence of } \\
\text { heart failure }\end{array}$ & {$[115]$} \\
\hline & LV GLS & $\begin{array}{l}\text { Independent predictor of arrhythmogenic } \\
\text { events in DCM }\end{array}$ & [46] \\
\hline & $\begin{array}{l}\text { Contractile reserve } \\
\text { at DSE }\end{array}$ & Predicts outcome & {$[24]$} \\
\hline \multirow[t]{4}{*}{$\begin{array}{l}\text { At } \\
\text { follow-up }\end{array}$} & LVRR & $\begin{array}{l}\text { Characterized by a decrease in LV } \\
\text { dimensions and normalization of } \mathrm{LV} \\
\text { shape associated with a significant } \\
\text { improvement of systolic function. It is } \\
\text { one of the main determinants of } \\
\text { prognosis }\end{array}$ & {$[27,92]$} \\
\hline & $\begin{array}{l}\text { Persistent vs. } \\
\text { reversible LV } \\
\text { restrictive filling } \\
\text { pattern }\end{array}$ & $\begin{array}{l}\text { Associated with subsequent mortality } \\
\text { and transplantation rate }\end{array}$ & {$[10]$} \\
\hline & $\begin{array}{l}\text { Improvement of } \\
\text { functional MR }\end{array}$ & $\begin{array}{l}\text { Early improvement is a favorable } \\
\text { independent prognostic factor }\end{array}$ & {$[107,108]$} \\
\hline & $\begin{array}{l}\text { Regression vs. } \\
\text { persistence or new } \\
\text { development of } \\
\text { RV systolic } \\
\text { dysfunction }\end{array}$ & $\begin{array}{l}\text { Independent risk factor of subsequent } \\
\text { outcome }\end{array}$ & {$[112,113]$} \\
\hline
\end{tabular}

$D C M$ dilated cardiomyopathy, $D S E$ dobutamine stress echocardiography, $E F$ ejection fraction, $E S V$ end-systolic volume, $F A C$ fractional area change, $G L S$ global longitudinal strain, $L A$ left atrial, $L V$ left ventricular, $L V R R$ left ventricular reverse remodeling, $M R$ mitral regurgitation, $R V$ right ventricular, $T R$ tricuspid regurgitation 
annular velocity $E^{\prime}$ at TDI ( $E / E^{\prime}$ ratio) is associated with exercise capacity in DCM [102]. $E / E^{\prime}$ ratio was also demonstrated to be a powerful predictor of clinical outcome in DCM patients [103]. Furthermore, baseline lateral $E / E^{\prime}$ ratio was an independent predictor for cardiac events in patients with heart failure treated with CRT [104].

LA enlargement is often observed in DCM as a consequence of LV diastolic dysfunction, functional MR, and atrial fibrillation. LA volume has incremental prognostic value in patients with DCM and correlates with exercise tolerance and pro-BNP [105].

Functional MR is independently associated with a poor prognosis in patients with LV dysfunction $[16,92,106]$. Improvement of functional MR in response to pharmacological therapy and CRT has been previously demonstrated [107]. Stolfo et al. [108] showed that in patients with DCM receiving optimal medical treatment, early improvement of functional MR is frequent (more than half of the cases) and is a favorable independent prognostic factor. Furthermore, early improvement of functional MR is frequently documented after CRT implantation in DCM and is associated with improved transplant-free survival [109]. With the emergence of percutaneous transcatheter MV procedures for the treatment of MR (MitraClip repair), the prognostic importance of correction of functional MR in DCM is likely to increase [110].

Concomitant RV dysfunction, in particular TAPSE $<14 \mathrm{~mm}$, represents an adverse prognostic marker in DCM [111].

The serial assessment of RV function by echocardiography is useful, particularly after optimization of medical therapy or after CRT. A regression of RV dysfunction is associated with a favorable transplant-free survival, whereas the persistence or the new development of RV systolic dysfunction is an independent risk factor of adverse outcome [112-114].

Functional TR is often associated with RV dilatation, RV dysfunction, or pulmonary hypertension. Pulmonary artery pressure measured from TR velocity provides additional prognostic information as peak TR velocity of more than $2.5 \mathrm{~m} / \mathrm{s}$ is associated with increased mortality, increased hospitalization, and higher incidence of heart failure [115].

A significant prolongation of QRS duration in the context of LBBB is the main marker of ventricular dyssynchrony used in trials of CRT [116]. Echocardiographic techniques may also detect mechanical dyssynchrony in some patients without significant QRS prolongation. However, in a large series of patients with systolic heart failure, echocardiographic evidence of LV dyssynchrony and a QRS duration of less than $130 \mathrm{~ms}$, CRT did not reduce the rate of death or hospitalization for heart failure and may increase mortality [117]. Therefore, assessment of dyssynchrony should not be part of the routine echocardiographic evaluation for patients with DCM and should be used in selected cases only.

Recent data demonstrated that the reversion after CRT treatment of simple qualitative echocardiographic signs of LV intraventricular dyssynchrony (septal flash and apical rocking) is a favorable prognostic sign and is associated with frequent improvement of LV function [118].

Few data are presently available about prognostic value of evaluation of LV strain by STE in DCM. LV subendocardial longitudinal function is often early 
deranged in DCM, and LV GLS is markedly decreased in DCM when compared with healthy controls [119]. As showed by Haugaa et al., LV GLS may be a valuable tool in the selection of candidates for CRT and independent predictor of arrhythmogenic events in DCM [46].

As previously stated, approximately one third of patients with DCM exhibit an improvement of LV function on optimal medical therapy. Merlo et al. [92] showed on a large cohort of patients with idiopathic DCM that LVRR (defined as a normalization or improvement of LV systolic function and a significant decrease in LV size) is related with more favorable outcomes in the long term. In this study, baseline independent predictors of LVRR were higher systolic blood pressure and the absence of LBBB. Notably, no baseline echocardiographic parameters were predictive of subsequent LVRR.

The implantation of an ICD in selected patients with DCM may prevent sudden cardiac death. Current international guidelines recommend ICD implantation in patients and previous cardiac arrest (secondary prevention) or in patients with severely reduced EF $(\leq 35 \%)$ and NYHA II/III despite optimal medical therapy (primary prevention) with a life expectancy $>1$ year [15]. It is recommended that patients should receive at least 3 months of optimal medical therapy before considering ICD implantation in primary prevention, as LVRR with recovery of systolic function may lead to unnecessary implantation. Patients that experience sudden death or major ventricular arrhythmias within the 6 months window after diagnosis are approximately 2\%; larger indexed LV ESV and QRS duration are predictors of early arrhythmic events [120].

Assessment of contractile reserve by DSE may be a useful tool to predict outcome in patients with DCM [121]. There is no general consensus on the definition of positive response to dobutamine in this specific context, but generally an increase in LVEF from rest to peak stress by $\geq 5$ points or a percentage change from baseline of $\geq 20 \%$ indicates the presence of contractile reserve [122]. Pinamonti et al. [24] investigated 51 patients with DCM with DSE and found that the addition of DSEderived information added a moderate but significant improvement of sensitivity to a model based only on rest echocardiography, with a general low predictive power. In addition, a reduced CFR during dipyridamole vasodilator test together with absence of contractile reserve provides additional negative prognostic value in DCM patients. CFR on left anterior descending artery less than 2 yields the worse prognosis [123].

In conclusion, echocardiography remains an extremely useful tool for the prognostic stratification of patients with DCM. The approach to echocardiographic interpretation should be holistic and not focused only on the LV systolic function or the regional wall motion abnormalities but also on the possible coexistence of diastolic impairment, valvular defects as functional MR, and other chamber dilatation. A serial echocardiographic assessment is mandatory in patients with DCM in order to capture possible improvements due to medical treatment and adverse progression of the disease, to clarify the possible presence of specific etiologies often characterized by reversibility of the systolic function (as myocarditis or alcoholic cardiomyopathy), and finally to select patients that may benefit from device therapy. 


\section{References}

1. Mestroni L, Maisch B, McKenna WJ, Schwartz K, Charron P, Rocco C, et al. Guidelines for the study of familial dilated cardiomyopathies. Collaborative Research Group of the European Human and Capital Mobility Project on Familial Dilated Cardiomyopathy. Eur Heart J. 1999;20:93-102.

2. Abate E, Pinamonti B, Porto A. Basic echocardiography in dilated cardiomyopathy. In: Pinamonti B, Sinagra G, editors. Clinical echocardiography and other imaging techniques in cardiomyopathies. New York: Springer; 2014.

3. Pinto YM, Elliott PM, Arbustini E, Adler Y, Anastasakis A, Böhm M, et al. Proposal for a revised definition of dilated cardiomyopathy, hypokinetic non-dilated cardiomyopathy, and its implications for clinical practice: a position statement of the ESC working group on myocardial and pericardial diseases. Eur Heart J. 2016;37:1850-8. https://doi.org/10.1093/eurheartj/ ehv727.

4. McNally EM, Mestroni L. Dilated cardiomyopathy: genetic determinants and mechanisms. Circ Res. 2017;121:731-48. https://doi.org/10.1161/CIRCRESAHA.116.309396.

5. Douglas PS, Morrow R, Ioli A, Reichek N. Left ventricular shape, afterload and survival in idiopathic dilated cardiomyopathy. J Am Coll Cardiol. 1989;13:311-5.

6. Gigli M, Stolfo D, Merlo M, Barbati G, Ramani F, Brun F, et al. Insights into mildly dilated cardiomyopathy: temporal evolution and long-term prognosis. Eur J Heart Fail. 2017;19:5319. https://doi.org/10.1002/ejhf.608.

7. Mestroni L, Morgera T, Miani D, Pinamonti B, Sinagra G, Tanganelli P, et al. Idiopathic left ventricular aneurysm: a clinical and pathological study of a new entity in the spectrum of cardiomyopathies. Postgrad Med J. 1994;70(Suppl 1):S13-20.

8. Günthard J, Stocker F, Bolz D, Jäggi E, Ghisla R, Oberhänsli I, et al. Dilated cardiomyopathy and thrombo-embolism. Eur J Pediatr. 1997;156:3-6.

9. Pinamonti B, Di Lenarda A, Sinagra G, Camerini F. Restrictive left ventricular filling pattern in dilated cardiomyopathy assessed by Doppler echocardiography: clinical, echocardiographic and hemodynamic correlations and prognostic implications. Heart Muscle Disease Study Group. J Am Coll Cardiol. 1993;22:808-15.

10. Pinamonti B, Zecchin M, Di Lenarda A, Gregori D, Sinagra G, Camerini F. Persistence of restrictive left ventricular filling pattern in dilated cardiomyopathy: an ominous prognostic sign. J Am Coll Cardiol. 1997;29:604-12.

11. Gorcsan J III, Abraham T, Agler DA, Bax JJ, Derumeaux G, Grimm RA, et al. Echocardiography for cardiac resynchronization therapy: recommendations for performance and reporting a report from the American Society of Echocardiography Dyssynchrony Writing Group endorsed by the Heart Rhythm Society. J Am Soc Echocardiogr. 2008;21:191-213. https://doi. org/10.1016/j.echo.2008.01.003.

12. Richardson M, Freemantle N, Calvert MJ, Cleland JG, Tavazzi L, CARE-HF Study Steering Committee and Investigators. Predictors and treatment response with cardiac resynchronization therapy in patients with heart failure characterized by dyssynchrony: a pre-defined analysis from the CARE-HF trial. Eur Heart J. 2007;28:1827-34.

13. De Boeck BW, Meine M, Leenders GE, Teske AJ, van Wessel H, Kirkels JH, et al. Practical and conceptual limitations of tissue Doppler imaging to predict reverse remodelling in cardiac resynchronisation therapy. Eur J Heart Fail. 2008;10:281-90. https://doi.org/10.1016/j. ejheart.2008.02.003.

14. Gorcsan J III. Role of echocardiography to determine candidacy for cardiac resynchronization therapy. Curr Opin Cardiol. 2008;23:16-22. https://doi.org/10.1097/HCO.0b013e3282f2e260.

15. Ponikowski P, Voors AA, Anker SD, Bueno H, Cleland JGF, Coats AJS, et al. 2016 ESC Guidelines for the diagnosis and treatment of acute and chronic heart failure. Eur Heart $\mathrm{J}$. 2016;37:2129-200. https://doi.org/10.1093/eurheartj/ehw128.

16. Junker A, Thayssen P, Nielsen B, Andersen PE. The hemodynamic and prognostic significance of echo-Doppler-proven mitral regurgitation in patients with dilated cardiomyopathy. Cardiology. 1993;83:14-20. 
17. Lancellotti P, Tribouilloy C, Hagendorff A, Popescu BA, Edvardsen T, Pierard LA, et al. Recommendations for the echocardiographic assessment of native valvular regurgitation: an executive summary from the European Association of Cardiovascular Imaging. Eur Heart $\mathbf{J}$ Cardiovasc Imaging. 2013;14:611-44. https://doi.org/10.1093/ehjci/jet105.

18. Thomas DE, Wheeler R, Yousef ZR, Masani ND. The role of echocardiography in guiding management in dilated cardiomyopathy. Eur J Echocardiogr. 2009;10:iii15-21. https://doi. org/10.1093/ejechocard/jep158.

19. Enriquez-Sarano M, Rossi A, Seward JB, Bailey KR, Tajik AJ. Determinants of pulmonary hypertension in left ventricular dysfunction. J Am Coll Cardiol. 1997;29:153-9.

20. Puwanant S, Priester TC, Mookadam F, Bruce CJ, Redfield MM, Chandrasekaran K. Right ventricular function in patients with preserved and reduced ejection fraction heart failure. Eur J Echocardiogr. 2009;10:733-7. https://doi.org/10.1093/ejechocard/jep052.

21. Pavlicek M, Wahl A, Rutz T, de Marchi SF, Hille R, Wustmann K, et al. Right ventricular systolic function assessment: rank of echocardiographic methods vs. cardiac magnetic resonance imaging. Eur J Echocardiogr. 2011;12:871-80. https://doi.org/10.1093/ejechocard/jer138.

22. Dini FL, Nuti R, Barsotti L, Baldini U, Dell'Anna R, Micheli G. Doppler-derived mitral and pulmonary venous flow variables are predictors of pulmonary hypertension in dilated cardiomyopathy. Echocardiography. 2002;19:457-65.

23. Lancellotti P, Pellikka PA, Budts W, Chaudhry FA, Donal E, Dulgheru R, et al. The clinical use of stress echocardiography in non-ischaemic heart disease: recommendations from the European Association of Cardiovascular Imaging and the American Society of Echocardiography. J Am Soc Echocardiogr. 2017;30:101-38.

24. Pinamonti B, Perkan A, Di Lenarda A, Gregori D, Sinagra G. Dobutamine echocardiography in idiopathic dilated cardiomyopathy: clinical and prognostic implications. Eur J Heart Fail. 2002;4:49-61.

25. Parsai C, Bijnens B, Sutherland GR, Baltabaeva A, Claus P, Marciniak M, et al. Toward understanding response to cardiac resynchronization therapy: left ventricular dyssynchrony is only one of multiple mechanisms. Eur Heart J. 2009;30:940-9. https://doi.org/10.1093/eurheartj/ ehn481.

26. Ennezat PV, Maréchaux S, Huerre C, Deklunder G, Asseman P, Jude B, et al. Exercise does not enhance the prognostic value of Doppler echocardiography in patients with left ventricular systolic dysfunction and functional mitral regurgitation at rest. Am Heart J. 2008;155:752-7. https://doi.org/10.1016/j.ahj.2007.11.022.

27. Merlo M, Cannatà A, Gobbo M, Stolfo D, Elliott PM, Sinagra G. Evolving concepts in dilated cardiomyopathy. Eur J Heart Fail. 2018;20:228-39. https://doi.org/10.1002/ejhf.1103.

28. Japp AG, Gulati A, Cook SA, Cowie MR, Prasad SK. The diagnosis and evaluation of dilated cardiomyopathy. J Am Coll Cardiol. 2016;67:2996-3010. https://doi.org/10.1016/j. jacc.2016.03.590.

29. Jan MF, Tajik AJ. Modern imaging techniques in cardiomyopathies. Circ Res. 2017;121:87491. https://doi.org/10.1161/CIRCRESAHA.117.309600.

30. Otterstad JE, Froeland G, Sutton SJ, Holme I. Accuracy and reproducibility of biplane twodimensional echocardiograph measurements of left ventricular dimensions and function. Eur Heart J. 1997;18:507-13.

31. Lang RM, Badano LP, Tsang W, Adams DH, Agricola E, Buck T, et al. EAE/ASE recommendation for image acquisition and display using three dimensional echocardiography. Eur Heart J Cardiovasc Imaging. 2012;13:1-46. https://doi.org/10.1016/j.echo.2011.11.010.

32. Lang RM, Badano LP, Mor-Avi V, Afilalo J, Armstrong A, Ernande L, et al. Recommendation for cardiac chamber quantification by echocardiograph in adults: an update from American Society of Echocardiography and the European Association of Cardiovascular Imaging. J Am Soc Echocardiogr. 2015;28:1-39. https://doi.org/10.1016/j.echo.2014.10.003.

33. Mu Y, Chen L, Tang Q, Ayoufu G. Real time three-dimensional echocardiographic assessment of left ventricular regional systolic function and dyssynchrony in patients with dilated cardiomyopathy. Echocardiography. 2010;27:415-20. https://doi. org/10.1111/j.1540-8175.2009.01028.x. 
34. Gutiérrez-Chico JL, Zamorano JL, Pérez de Isla L, Orejas M, Almería C, Rodrigo JL, et al. Comparison of left ventricular volumes and ejection fraction measured by three-dimensional echocardiography versus by two-dimensional echocardiography and cardiac magnetic resonance in patient with various cardiomyopathies. Am J Cardiol. 2005;95:809-13.

35. Shiota T, McCarthy PM, White RD, Qin JX, Greenberg NL, Flamm SD, et al. Initial clinical experience of real-time three-dimensional echocardiography in patients with ischemic and idiopathic dilated cardiomyopathy. Am J Cardiol. 1999;84:1068-73.

36. Gopal AS, Schnellbaecher MJ, Shen Z, Boxt LM, Katz J, King DL. Freehand three-dimensional echocardiography for determination of left ventricular volume and mass in patients with abnormal ventricles: comparison with magnetic resonance imaging. J Am Soc Echocardiogr. 1997;10:853-61.

37. Mor-Avi V, Sugeng L, Weinert L, MacEneaney P, Caiani EG, Koch R, et al. Fast measurements of left ventricular mass with real-time three-dimensional echocardiography: comparison with magnetic resonance imaging. Circulation. 2004;110:1814-8.

38. Shimada YJ, Shiota T. A meta-analysis and investigation for the source of bias of left ventricular volumes and function by three-dimensional echocardiography in comparison with magnetic resonance imaging. Am J Cardiol. 2011;107:126-38. https://doi.org/10.1016/j. amjcard.2010.08.058.

39. Mor-Avi V, Jenkins C, Kühl HP, Nesser HJ, Marwick T, Franke A, et al. Real-time 3-dimensional echocardiography quantification of left ventricular volumes: multicenter study for validation with magnetic resonance imaging and investigation of source of error. J Am Coll Cardiol Img. 2008;1:413-23. https://doi.org/10.1016/j.jcmg.2008.02.009.

40. Shan K, Bick RJ, Poindexter BJ, Shimoni S, Letsou GV, Reardon MJ, et al. Relation of tissue Doppler derived myocardial velocities to myocardial structure and beta-adrenergic receptor density in humans. J Am Coll Cardiol. 2011;36:891-6.

41. Takamura T, Dohi K, Onishi K, Tanabe M, Sugiura E, Nakajima H, et al. Left ventricular contraction-relaxation coupling in normal, hypertrophic and failing myocardium quantified by speckle-tracking global strain and strain rate imaging. J Am Soc Echocardiogr. 2010;23:74754. https://doi.org/10.1016/j.echo.2010.04.005.

42. Meluzin J, Spinarova L, Hude P, Krejci J, Poloczkova H, Podrouzkova H, et al. Left ventricular mechanics in idiopathic dilated cardiomyopathy: systolic-diastolic coupling and torsion. J Am Soc Echocardiogr. 2009;22:486-93. https://doi.org/10.1016/j.echo.2009.02.022.

43. Zeng S, Zhou QC, Peng QH, Cao DM, Tian LQ, Ao K, et al. Assessment of regional myocardial function in patients with dilated cardiomyopathy by velocity vector imaging. Echocardiography. 2009;26:163-70. https://doi.org/10.1111/j.1540-8175.2008.00797.x.

44. Jasaityte R, Dandel M, Lehmkuhl H, Hetzer R. Prediction of short-term outcomes in patients with idiopathic dilated cardiomyopathy referred for transplantation using standard echocardiography and strain imaging. Transplant Proc. 2009;41:277-80. https://doi.org/10.1016/j. transproceed.2008.10.083.

45. Friedberg MK, Slorach C. Relation between left ventricular regional radial function and radial wall motion abnormalities using two-dimensional speckle tracking in children with idiopathic dilated cardiomyopathy. Am J Cardiol. 2008;102:335-9. https://doi.org/10.1016/j. amjcard.2008.03.064.

46. Haugaa KH, Goebel B, Dahlslett T, Meyer K, Jung C, Lauten A, et al. Risk assessment of ventricular arrhythmias in patients with nonischemic dilated cardiomyopathy by strain echocardiography. J Am Soc Echocardiogr. 2012;25:667-73. https://doi.org/10.1016/j. echo.2012.02.004.

47. Spartera M, Damascelli A, Mozes F, De Cobelli F, La Canna G. Three-dimensional speckle tracking longitudinal strain is related to myocardial fibrosis determined by late-gadolinium enhancement. Int J Cardiovasc Imaging. 2017;33:1351-60. https://doi.org/10.1007/ s10554-017-1115-1.

48. Russel IK, Gotte MJ, Bronzwaer JG, Knaapen P, Paulus WJ, van Rossum AC. Left ventricular torsion: an expanding role in the analysis of myocardial dysfunction. JACC Cardiovasc Imaging. 2009;2:648-55. https://doi.org/10.1016/j.jcmg.2009.03.001. 
49. Sveric KM, Ulbrich S, Rady M, Ruf T, Kvakan H, Strasser RH, et al. Three-dimensional left ventricular torsion in patients with dilated cardiomyopathy. Circ J. 2017;81:529-36. https:// doi.org/10.1253/circj.CJ-16-0965.

50. Matsumoto K, Tanaka H, Tatsumi K, Miyoshi T, Hiraishi M, Kaneko A, et al. Left ventricular dyssynchrony using three-dimensional speckle-tracking imaging as a determinant of torsional mechanics in patients with idiopathic dilated cardiomyopathy. Am J Cardiol. 2012;109:1197205. https://doi.org/10.1016/j.amjcard.2011.11.059.

51. Sade LE, Demir Ö, Atar I, Müderrinsoglu H, Özin B. Effect of mechanical dyssynchrony and cardiac resynchronization therapy on the left ventricular rotational mechanics. Am J Cardiol. 2008;101:1163-9. https://doi.org/10.1016/j.amjcard.2007.11.069.

52. Jenkins C, Bricknell K, Hanekom L, Marwick TH. Reproducibility of accuracy of echocardiographic measurements of left ventricular parameters using real-time three-dimensional echocardiography. J Am Coll Cardiol. 2004;44:878-86.

53. Qin JX, Jones M, Travaglini A, Song JM, Li J, White RD, et al. The accuracy of left ventricular mass determined by real-time three-dimensional echocardiography in chronic animal and clinical studies: a comparison with postmortem examination and magnetic resonance imaging. J Am Soc Echocardiogr. 2005;18:1037-43.

54. Chung ES, Leon AR, Tavazzi L, Sun JP, Nihoyannopoulos P, Merlino J, et al. Results of the Predictors of Response to CRT (PROSPECT) trial. Circulation. 2008;117:2608-16. https://doi. org/10.1161/CIRCULATIONAHA.107.743120.

55. Marsan NA, Bleeker GB, Ypenburg C, Ghio S, van de Veire NR, Holman ER, et al. Realtime three-dimensional echocardiography permits quantification of left ventricular mechanical dyssynchrony and predicts acute response to cardiac resynchronization therapy. J Cardiovasc Electrophysiol. 2008;19:392-9. https://doi.org/10.1111/j.1540-8167.2007.01056.x.

56. Marsan NA, Bleeker GB, Ypenburg C, Van Bommel RJ, Ghio S, Van de Veire NR, et al. Realtime three-dimensional echocardiography as a novel approach to assess left ventricular and left atrium reverse remodeling and to predict response to cardiac resynchronization therapy. Heart Rhythm. 2008;5:1257-64. https://doi.org/10.1016/j.hrthm.2008.05.021.

57. Kleijn SA, van Dijk J, de Cock CC, Allaart CP, van Rossum AC, Kamp O. Assessment of intraventricular mechanical dyssynchrony and prediction of response to cardiac resynchronization therapy: comparison between tissue Doppler imaging and real-time three-dimensional echocardiography. J Am Soc Echocardiogr. 2009;22:1047-54. https://doi.org/10.1016/j. echo.2009.06.012.

58. Soliman OI, Geleijnse ML, Theuns DA, van Dalen BM, Vletter WB, Jordaens LJ, et al. Usefulness of left ventricular systolic dyssynchrony by real-time three-dimensional echocardiography to predict long-term response to cardiac resynchronization therapy. Am J Cardiol. 2009;103:1586-91. https://doi.org/10.1016/j.amjcard.2009.01.372.

59. Delgado V, Ypenburg C, van Bommel RJ, Tops LF, Mollema SA, Marsan NA, et al. Assessment of left ventricular dyssynchrony by speckle tracking strain imaging comparison between longitudinal, circumferential, and radial strain in cardiac resynchronization therapy. J Am Coll Cardiol. 2008;51:1944-52. https://doi.org/10.1016/j.jacc.2008.02.040.

60. Tanaka H, Nesser HJ, Buck T, Oyenuga O, Jánosi RA, Winter S, et al. Dyssynchrony by speckle-tracking echocardiography and response to cardiac resynchronization therapy: results of the Speckle Tracking and Resynchronization (STAR) study. Eur Heart J. 2010;31:1690-700. https://doi.org/10.1093/eurheartj/ehq213.

61. D'Andrea A, Caso P, Scarafile R, Riegler L, Salerno G, Castaldo F, et al. Effects of global longitudinal strain and total scar burden on response to cardiac resynchronization therapy in patients with ischaemic dilated cardiomyopathy. Eur J Heart Fail. 2009;11:58-67. https://doi. org/10.1093/eurjhf/hfn010.

62. Tanaka H, Hara H, Saba S, Gorcsan J III. Usefulness of three-dimensional speckle tracking strain to quantify dyssynchrony and the site of latest mechanical activation. Am J Cardiol. 2010;105:235-42. https://doi.org/10.1016/j.amjcard.2009.09.010.

63. Mullens W, Borowski AG, Curtin RJ, Thomas JD, Tang WH. Tissue Doppler imaging in the estimation of intracardiac filling pressure in decompensated patients with 
advanced systolic heart failure. Circulation. 2009;119:62-70. https://doi.org/10.1161/ CIRCULATIONAHA.108.779223.

64. Meluzin J, Spinarova L, Hude P, Krejci J, Podrouzkova H, Pesl M, et al. Estimation of left ventricular filling pressure by speckle tracking echocardiography in patients with idiopathic dilated cardiomyopathy. Eur J Echocardiogr. 2011;12:11-8. https://doi.org/10.1093/ ejechocard/jeq088.

65. Cameli M, Lisi M, Mondillo S, Padeletti M, Ballo P, Tsioulpas C, et al. Left atrial longitudinal strain by speckle tracking echocardiography correlates well with left ventricular filling pressures in patients with heart failure. Cardiovasc Ultrasound. 2010;8:14. https://doi. org/10.1186/1476-7120-8-14.

66. Guler A, Tigen KM, Dundar C, Karaahmet T, Karabay CY, Aung SM, et al. Left atrial deformation and nonischaemic dilated cardiomyopathy. A 2D speckle-tracking imaging study. Herz. 2014;39:251-7. https://doi.org/10.1007/s00059-013-3817-z.

67. D'Andrea A, Caso P, Romano S, Scarafile R, Cuomo S, Salerno G, et al. Association between left atrial myocardial function and exercise capacity in patients with either idiopathic or ischemic dilated cardiomyopathy: a two-dimensional speckle strain study. Int J Cardiol. 2009;132:354-63. https://doi.org/10.1016/j.ijcard.2007.11.102.

68. Thavendiranathan P, Phelan D, Collier P, Thomas JD, Flamm SD, Marwick TH. Quantitative assessment of mitral regurgitation: how best to do it. JACC Cardiovasc Imaging. 2012;5:116175. https://doi.org/10.1016/j.jcmg.2012.07.013.

69. Kahlert P, Plicht B, Schenk IM, Janosi RA, Erbel R, Bluck T. Direct assessment of size and shape of non circular vena contracta area in functional versus organic mitral regurgitation using real-time three-dimensional echocardiography. J Am Soc Echocardiogr. 2008;21:912-21. https://doi.org/10.1016/j.echo.2008.02.003.

70. Otsuji Y, Handschumacher MD, Schwammenthal E, Jiang L, Song JK, Guerrero JL, et al. Insight from three-dimensional echocardiography into the mechanism of functional mitral regurgitation: direct in vivo demonstration of altered leaflet tethering geometry. Circulation. 1997;96:1999-2008.

71. Buck T, Plicht B. Real-time three dimensional echocardiographic assessment of severity of mitral regurgitation using proximal isovelocity surface area and vena contracta area method. lesson we learned and clinical implication. Curr Cardiovasc Imaging Rep. 2015;8:38.

72. Iwakura K, Ito H, Kawano S, Okamura A, Kurotobi T, Date M, et al. Comparison of orifice area by transthoracic three-dimensional Doppler echocardiography versus proximal isovelocity surface area (PISA) method for assessment of mitral regurgitation. Am J Cardiol. 2006;97:1630-7.

73. Marsan NA, Westenberg JJ, Ypenburg C, Delgado V, van Bommel RJ, Roes SD, et al. Quantification of functional mitral regurgitation by real-time 3D echocardiography. JACC Cardiovasc Imaging. 2009;2:1245-52. https://doi.org/10.1016/j.jcmg.2009.07.006.

74. Acquila I, Fernandéz-Golfín C, Rincon LM, Gonzales A, Garcia-Martin A, Hinojar R, et al. Fully automated software for mitral annulus evaluation in chronic mitral regurgitation by 3-dimensional transesophageal echocardiography. Medicine (Baltimore). 2015;95:e5387. https://doi.org/10.1097/MD.0000000000005387.

75. Acquila I, GonzálezA, Fernandéz-Golfín C, Rincon LM, Casas E, GarciaA, et al. Reproducibility of a novel echocardiographic 3D automated software for the assessment of mitral valve anatomy. Cardiovasc Ultrasound. 2016;14:17. https://doi.org/10.1186/s12947-016-0061-8.

76. Lancellotti P, Zamorano JL, Vannan M. Imaging challenges in secondary mitral regurgitation: unsolved issue and perspectives. Circ Cardiovasc Imaging. 2014;7:735-46. https://doi. org/10.1161/CIRCIMAGING.114.000992.

77. Wunderlich NC, Siegel RJ. Peri-interventional echo assessment for the MitraClip procedure. Eur Heart J Cardiovasc Imaging. 2013;14:935-49. https://doi.org/10.1093/ehjci/jet060.

78. Salerno G, D'Andrea A, Bossone E, Scarafile R, Riegler L, Di Salvo G, et al. Association between right ventricular two-dimensional strain and exercise capacity in patients with either idiopathic or ischemic dilated cardiomyopathy. J Cardiovasc Med (Hagerstown). 2011;12:62534. https://doi.org/10.2459/JCM.0b013e328349a268. 
79. D’Andrea A, Gravino R, Riegler L, Salerno G, Scarafile R, Romano M, et al. Right ventricular ejection fraction and left ventricular dyssynchrony by 3D echo correlate with functional impairment in patients with dilated cardiomyopathy. J Card Fail. 2011;17:309-17. https://doi. org/10.1016/j.cardfail.2010.11.005.

80. Rapezzi C, Arbustini E, Caforio AL, Charron P, Gimeno-Blanes J, Heliö T, et al. Diagnostic work-up in cardiomyopathies: bridging the gap between clinical phenotypes and final diagnosis. A position statement from the ESC Working Group on Myocardial and Pericardial Diseases. Eur Heart J. 2013;34:1448-58. https://doi.org/10.1093/eurheartj/ehs397.

81. Bozkurt B, Colvin M, Cook J, Cooper LT, Deswal A, Fonarow GC, et al. Current diagnostic and treatment strategies for specific dilated cardiomyopathies: a scientific statement from the American Heart Association. Circulation. 2016;134:579-646.

82. Bobbo M, Pinamonti B, Merlo M, Stolfo D, Iorio A, Ramani F, et al. Comparison of patient characteristics and course of hypertensive hypokinetic cardiomyopathy versus idiopathic dilated cardiomyopathy. Am J Cardiol. 2017;119:483-9. https://doi.org/10.1016/j. amjcard.2016.10.014.

83. Pinamonti B, Alberti E, Cigalotto A, Dreas L, Salvi A, Silvestri F, et al. Echocardiographic findings in myocarditis. Am J Cardiol. 1988;62:285-91.

84. Dragos AM, Pinamonti B, Abate E. Basic echocardiography in arrhythmogenic right ventricular cardiomyopathy. In: Pinamonti B, Sinagra G, editors. Clinical echocardiography and other imaging techniques in cardiomyopathies. New York: Springer; 2014.

85. Blake LM, Scheinman MM, Higgins CB. MR features of arrhythmogenic right ventricular dysplasia. AJR Am J Roentgenol. 1994;162:809-12.

86. Finocchiaro G, Pinamonti B, Abate E. Basic echocardiography in hypertrophic cardiomyopathy. In: Pinamonti B, Sinagra G, editors. Clinical echocardiography and other imaging techniques in cardiomyopathies. New York: Springer; 2014.

87. Moretti M, Fabris E, Finocchiaro G, et al. Infiltrative/storage cardiomyopathies: clinical assessment and imaging in diagnosis and patient management. In: Pinamonti B, Sinagra G, editors. Clinical echocardiography and other imaging techniques in cardiomyopathies. New York: Springer; 2014.

88. Martin CA, Lambiase PD. Pathophysiology, diagnosis and treatment of tachycardiomyopathy. Heart. 2017;103:1543-52. https://doi.org/10.1136/heartjnl-2016-310391.

89. Moretti M, Merlo M, Barbati G, Di Lenarda A, Brun F, Pinamonti B, et al. Prognostic impact of familial screening in dilated cardiomyopathy. Eur J Heart Fail. 2010;12:922-7. https://doi. org/10.1093/eurjhf/hfq093.

90. Mahon NG, Murphy RT, MacRae CA, Caforio AL, Elliott PM, McKenna WJ. Echocardiographic evaluation in asymptomatic relatives of patients with dilated cardiomyopathy reveals preclinical disease. Ann Intern Med. 2005;143:108-15.

91. Murtaza G, Virk HUH, Khalid M, Rahman Z, Sitwala P, Schoondyke J, et al. Role of speckle tracking echocardiography in dilated cardiomyopathy: a review. Cureus. 2017;9:e1372. https:// doi.org/10.7759/cureus.1372.

92. Merlo M, Pyxaras SA, Pinamonti B, Barbati G, Di Lenarda A, Sinagra G. Prevalence and prognostic significance of left ventricular reverse remodeling in dilated cardiomyopathy receiving tailored medical treatment. J Am Coll Cardiol. 2011;57:1468-76. https://doi.org/10.1016/j. jacc.2010.11.030.

93. Merlo M, Pivetta A, Pinamonti B, Stolfo D, Zecchin M, Barbati G, et al. Long-term prognostic impact of therapeutic strategies in patients with idiopathic dilated cardiomyopathy: changing mortality over the last 30 years. Eur J Heart Fail. 2014;16:317-24. https://doi.org/10.1002/ ejhf.16.

94. Zecchin M, Lenarda AD, Bonin M, Mazzone C, Zanchi C, Di Chiara C, et al. Incidence and predictors of sudden cardiac death during long-term follow-up in patients with dilated cardiomyopathy on optimal medical therapy. Ital Heart J. 2001;2:213-21.

95. Zecchin M, Merlo M, Pivetta A, Barbati G, Lutman C, Gregori D, et al. How can optimization of medical treatment avoid unnecessary implantable cardioverter-defibrillator implantations in patients with idiopathic dilated cardiomyopathy presenting with "SCD-HeFT criteria?". Am J Cardiol. 2012;109:729-35. https://doi.org/10.1016/j.amjcard.2011.10.033. 
96. Stolfo D, De Luca A, Morea G, Merlo M, Vitrella G, Caiffa T, et al. Predicting device failure after percutaneous repair of functional mitral regurgitation in advanced heart failure: implications for patient selection. Int J Cardiol. 2018;257:182-7. https://doi.org/10.1016/j. ijcard.2018.01.009.

97. Di Lenarda A, Secoli G, Perkan A, Gregori D, Lardieri G, Pinamonti B, et al. Changing mortality in dilated cardiomyopathy. The Heart Muscle Disease Study Group. Br Heart J. 1994;72(6 Suppl):S46-51.

98. Sinagra G, Sabbadini G, Di Lenarda A, Gortan R, Massa L, Carniel E, et al. [Changes in medical treatment of heart failure in the light of large clinical trials]. Ital Heart J Suppl. 2001;2:97-115.

99. Di Lenarda A, Pinamonti B, Mestroni L, Salvi A, Sabbadini G, Gregori D, et al. [The natural history of dilated cardiomyopathy: a review of the Heart Muscle Disease Registry of Trieste]. Ital Heart J Suppl. 2004;5:253-66.

100. Faris R, Coats AJ, Henein MY. Echocardiography-derived variables predict outcome in patients with nonischemic dilated cardiomyopathy with or without a restrictive filling pattern. Am Heart J. 2002;144:343-50.

101. Puggia I, Merlo M, Barbati G, Rowland TJ, Stolfo D, Gigli M et al. Natural history of dilated cardiomyopathy in children. J Am Heart Assoc. 2016;5(7). https://doi.org/10.1161/ JAHA.116.003450.

102. Zambon E, Iorio A, Di Nora C, Carriere C, Abate E, Merlo M, et al. Left ventricular function and exercise performance in idiopathic dilated cardiomyopathy: role of tissue Doppler imaging. J Cardiovasc Med (Hagerstown). 2017;18:230-6. https://doi.org/10.2459/ JCM.0000000000000411.

103. Galrinho A, Branco L, Soares R, Timóteo A, Abreu J, Leal A, et al. Prognostic implications of tissue Doppler in patients with dilated cardiomyopathy. Rev Port Cardiol. 2006;25:781-93.

104. Soliman OI, Theuns DA, ten Cate FJ, Anwar AM, Nemes A, Vletter WB, et al. Baseline predictors of cardiac events after cardiac resynchronization therapy in patients with heart failure secondary to ischemic or nonischemic etiology. Am J Cardiol. 2007;100:464-9.

105. Galrinho A, Branco LM, Soares RM, Miranda F, Leal A, Ferreira RC. Left atrial volume: an old echocardiographic measure with renewed prognostic significance: a study in patients with dilated cardiomyopathy. Rev Port Cardiol. 2009;28:1049-60.

106. Rossi A, Dini FL, Faggiano P, Agricola E, Cicoira M, Frattini S, et al. Independent prognostic value of functional mitral regurgitation in patients with heart failure. A quantitative analysis of 1256 patients with ischaemic and non-ischaemic dilated cardiomyopathy. Heart. 2011;97:1675-80. https://doi.org/10.1136/hrt.2011.225789.

107. van Bommel RJ, Marsan NA, Delgado V, Borleffs CJ, van Rijnsoever EP, Schalij MJ, et al. Cardiac resynchronization therapy as a therapeutic option in patients with moderate-severe functional mitral regurgitation and high operative risk. Circulation. 2011;124:912-9. https:// doi.org/10.1161/CIRCULATIONAHA.110.009803.

108. Stolfo D, Merlo M, Pinamonti B, Poli S, Gigli M, Barbati G, et al. Early improvement of functional mitral regurgitation in patients with idiopathic dilated cardiomyopathy. Am J Cardiol. 2015;115:1137-43. https://doi.org/10.1016/j.amjcard.2015.01.549.

109. Stolfo D, Tonet E, Barbati G, Gigli M, Pinamonti B, Zecchin M, et al. Acute hemodynamic response to cardiac resynchronization in dilated cardiomyopathy: effect on late mitral regurgitation. Pacing Clin Electrophysiol. 2015;38:1287-96. https://doi.org/10.1111/pace.12731.

110. Kamperidis V, van Wijngaarden SE, van Rosendael PJ, Kong WKF, Regeer MV, van der Kley F, et al. Mitral valve repair for secondary mitral regurgitation in non-ischaemic dilated cardiomyopathy is associated with left ventricular reverse remodelling and increase of forward flow. Eur Heart J Cardiovasc Imaging. 2018;19:208-15. https://doi.org/10.1093/ehjci/jex011.

111. Ghio S, Recusani F, Klersy C, Sebastiani R, Laudisa ML, Campana C, et al. Prognostic usefulness of the tricuspid annular plane systolic excursion in patients with congestive heart failure secondary to idiopathic or ischemic dilated cardiomyopathy. Am J Cardiol. 2000;85:837-42.

112. Merlo M, Gobbo M, Stolfo D, Losurdo P, Ramani F, Barbati G, et al. The prognostic impact of the evolution of RV function in idiopathic DCM. JACC Cardiovasc Imaging. 2016;9:103442. https://doi.org/10.1016/j.jcmg.2016.01.027. 
113. Pueschner A, Chattranukulchai P, Heitner JF, Shah DJ, Hayes B, Rehwald W, et al. The prevalence, correlates, and impact on cardiac mortality of right ventricular dysfunction in nonischemic cardiomyopathy. JACC Cardiovasc Imaging. 2017;10(10 Pt B):1225-36. https://doi. org/10.1016/j.jcmg.2017.06.013.

114. Stolfo D, Tonet E, Merlo M, Barbati G, Gigli M, Pinamonti B, et al. Early right ventricular response to cardiac resynchronization therapy: impact on clinical outcomes. Eur J Heart Fail. 2016;18:205-13. https://doi.org/10.1002/ejhf.450.

115. Hung J, Koelling T, Semigran MJ, Dec GW, Levine RA, Di Salvo TG. Usefulness of echocardiographic determined tricuspid regurgitation in predicting event-free survival in severe heart failure secondary to idiopathic-dilated cardiomyopathy or to ischemic cardiomyopathy. Am J Cardiol. 1998;82:1301-3, A10.

116. Cleland JG, Daubert JC, Erdmann E, Freemantle N, Gras D, Kappenberger L, et al. The effect of cardiac resynchronization on morbidity and mortality in heart failure. N Engl J Med. 2005;352:1539-49.

117. Ruschitzka F, Abraham WT, Singh JP, Bax JJ, Borer JS, Brugada J, et al. Cardiacresynchronization therapy in heart failure with a narrow QRS complex. N Engl J Med. 2013;369:1395-405. https://doi.org/10.1056/NEJMoa1306687.

118. Stankovic I, Prinz C, Ciarka A, Daraban AM, Kotrc M, Aarones M, et al. Relationship of visually assessed apical rocking and septal flash to response and long-term survival following cardiac resynchronization therapy (PREDICT-CRT). Eur Heart J Cardiovasc Imaging. 2016;17:262-9. https://doi.org/10.1093/ehjci/jev288.

119. Abduch MC, Salgo I, Tsang W, Vieira ML, Cruz V, Lima M, et al. Myocardial deformation by speckle tracking in severe dilated cardiomyopathy. Arq Bras Cardiol. 2012;99:834-43.

120. Losurdo P, Stolfo D, Merlo M, Barbati G, Gobbo M, Gigli M et al. Early arrhythmic events in idiopathic dilated cardiomyopathy. JACC Clin Electrophysiol. 2016;2(5). https://doi. org/10.1016/j.jacep.2016.05.002.

121. Drozd J, Krzeminska-Pakula M, Plewka M, Ciesielczyk M, Kasprzak JD. Prognostic value of low-dose dobutamine echocardiography in patients with dilated cardiomyopathy. Chest. 2002;121:1216-22.

122. Neskovic AN, Otasevic P. Stress-echocardiography in idiopathic dilated cardiomyopathy: instructions for use. Cardiovasc Ultrasound. 2005;3:3. https://doi.org/10.1186/1476-7120-3-3.

123. Rigo F, Gherardi S, Galderisi M, Pratali L, Cortigiani L, Sicari R, et al. The prognostic impact of coronary flow reserve assessed by Doppler echocardiography in non ischemic dilated cardiomyopathy. Eur Heart J. 2006;27:1319-23.

Open Access This chapter is licensed under the terms of the Creative Commons Attribution 4.0 International License (http://creativecommons.org/licenses/by/4.0/), which permits use, sharing, adaptation, distribution and reproduction in any medium or format, as long as you give appropriate credit to the original author(s) and the source, provide a link to the Creative Commons license and indicate if changes were made.

The images or other third party material in this chapter are included in the chapter's Creative Commons license, unless indicated otherwise in a credit line to the material. If material is not included in the chapter's Creative Commons license and your intended use is not permitted by statutory regulation or exceeds the permitted use, you will need to obtain permission directly from the copyright holder.

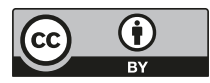

